\title{
البيئة والتحول نحو الاستدامة: نظرة إسلامية
}

\section{عودة الجيوسي}

$$
\begin{aligned}
& \text { الملخص } \\
& \text { يهدف هذا البحث إلى إلقاء الضوء على التصور الإسلامي لفكرة التنمية الإسلامية، ونقد الفكر الغربي وما }
\end{aligned}
$$

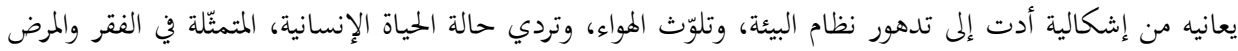

$$
\begin{aligned}
& \text { والجموع، وصولاً إلى تبيان مدى الخلل الحاصل في الأنظمة البيئية نتيجة نسق التفكير الغربي، ونمط التنمية الغربية اللذين ولني } \\
& \text { يعتمدان مبدأ النمو لأجل النمو، وتشجيع الاستهلاك، وحتى ربطه بمفهوم السعادة. يهدف البحث كذلك إلى طرح }
\end{aligned}
$$

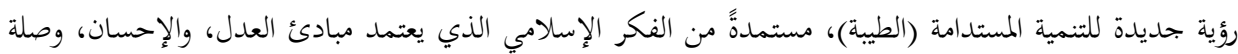

$$
\begin{aligned}
& \text { الرحم، والحد من الفساد. } \\
& \text { الكلمات المفتاحية: البيئة، التنمية المستدامة، الاسلام، الاستدامة، الفكر البيئي، الفلسفة البيئية. }
\end{aligned}
$$

\section{Ecology and Sustainable Development: An Islamic Worldview}

\section{Abstract}

This article intends to shed some light on the Islamic worldview of sustainable development. It also aims to critique the underpinnings of the western model of development which led to ecological degradation, poverty, pollution, waste and new types of chronic diseases. It highlights the pitfalls of the notion of "growth for the sake of growth" which has resulted in a misuse and overconsumption of resources. The paper also presents a proposed conceptual framework that is based on justice (adl); beauty (ihsan); protection of social and human capital (arham) and control of corruption (fassad).

Keywords: environment, sustainable development, Islam, sustainability, environmental thought, environmental philosophy

" دكتوراه في تخطيط المدن وتحليل السياسات العامة، جامعة إلينوي/الولايات المتحدة. نائب الرئيس -للعلوم والبحث-

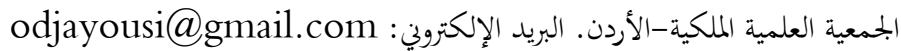

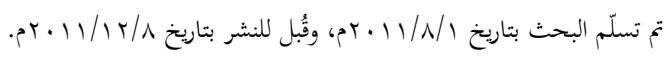




\section{مقدمة:}

شـهـد مطلـع القـرن الحــادي والعشـرين نقاشـاً مستفيضـاً حــول قضــايا: البيئسة،

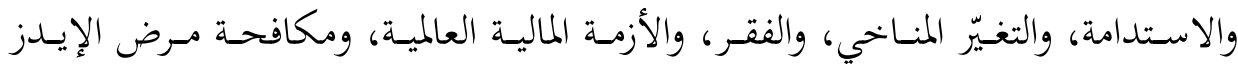

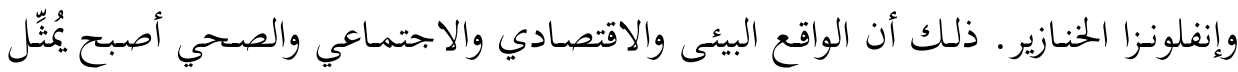

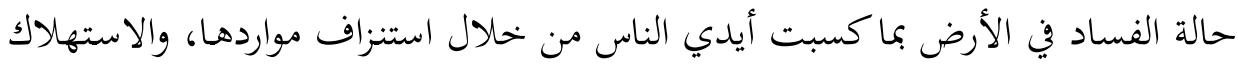

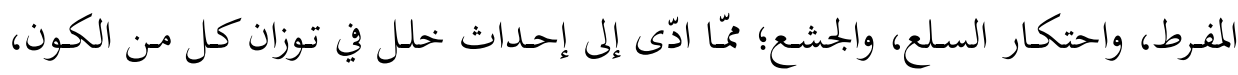
والإنسان، والحياة. '

لقـد أرسى الإسلام؛ بوصفه رسالة ومـنهج حياة، مبـادئ وأسساً للعلاقة بين الفرد

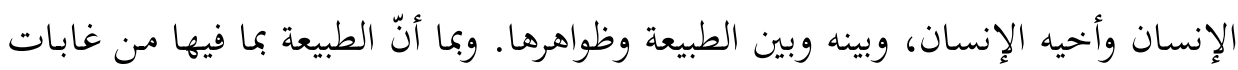

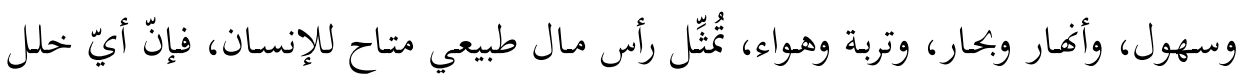

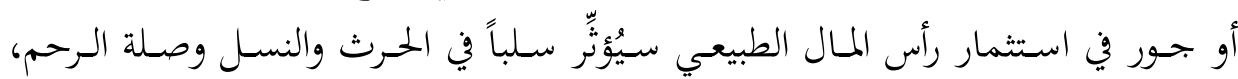

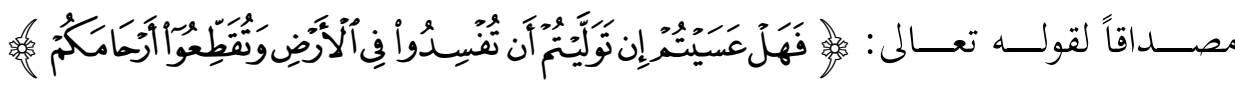

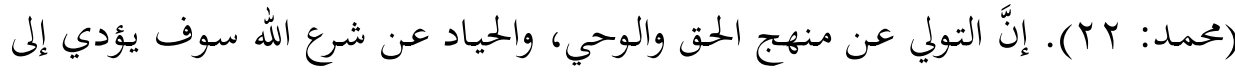

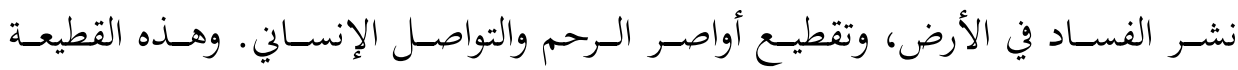

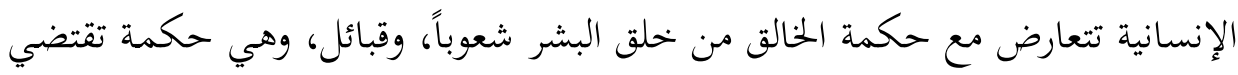

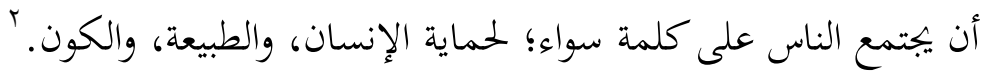

يهـــف هـذا البحــث إلى إلقــاء الضـوء علـى التصـور الإسـلامي لفكـرة التنميـة

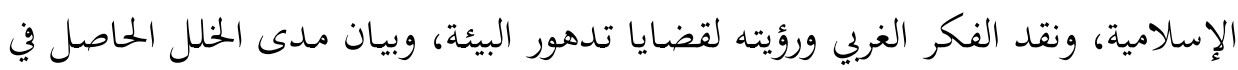

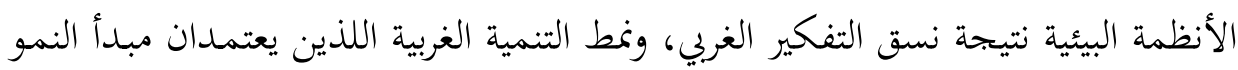

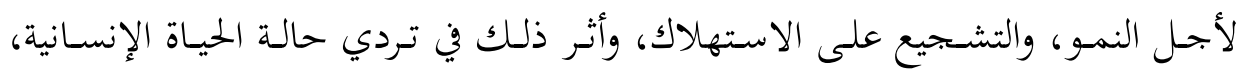

${ }^{1}$ Adams, W. M. and S. J. Jeanrenaud. Transition to sustainability. Gland, Switzerland: World Conservation Union. 2009. pp.8-30.

2 Al-Jayyousi, Odeh. R. Islamic principles and Dublin statement, Water Management in Islam. Editors: Faruqui et al. Tokyo: United Nations University Press, IDRC, 2001, pp. 33-38. 
المتمثّلة في الفقر والمرض والجوع. كما يهدف البحث إلى تطوير خطاب إسلامي معاصر

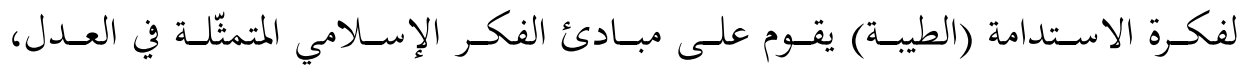

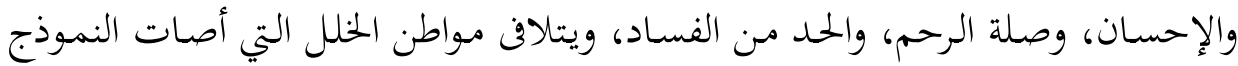
الغربي في ما يخص البيئة.

تكمـن أهميـة هـذا البحـث أيضـاً في ملاحظة ظـواهر التغيّر المنـاخي ومـا رافقـهـ مـن

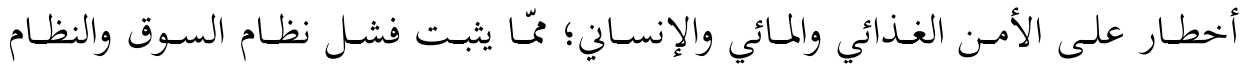

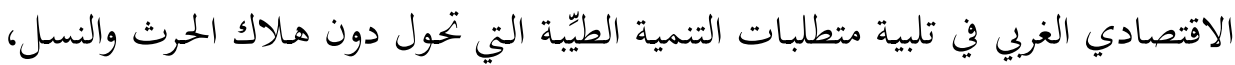
وإلحاق الضرر بالأرض ومَن عليها.

\section{مدخل تأسيسي لفكرة الاستدامة:}

ترجع فكرة الاستدامة إلى هاية الستينيات من القرن الماضي؛ إذ عمل الاتحاد الدولي

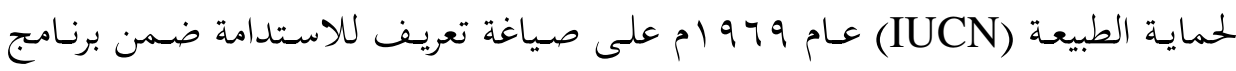

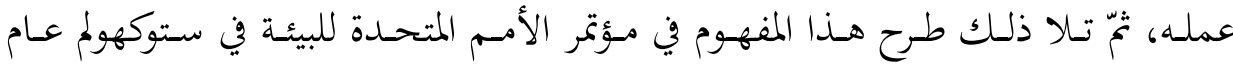

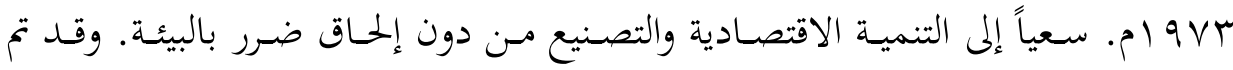

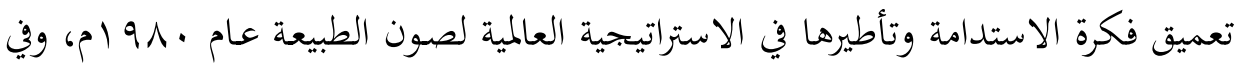

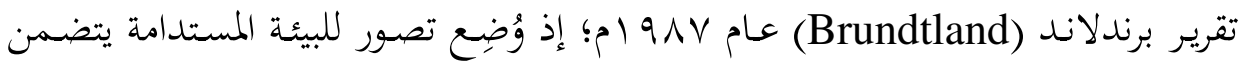

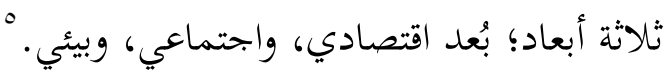

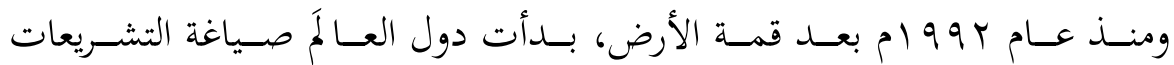
والاتفاقيات الخاصة بالبيئة، مثل اتفاقية كيوتو للحد من التغيّر المناخي، فضلاً عن إشراك القطاع الخاص والمحتمع المدني في حماية البيئة وتخضير الصناعة، ولكنّ المفارقة التي نعيشها

${ }^{3} \mathrm{Al}$ - Jayyousi, Odeh. The State of Ecosystems and Progress of Societies, Statistics, Knowledge and Policy. Measuring and fostering the progress of societies. OECD, 2008, pp. 441-451.

${ }^{4}$ Al-Jayyousi, Odeh. Islamic values and rural sustainable development. Rural 21 Journal, Germany, 2009, pp. 39-41.

5 WCSD. Report of the World Commission on Environment and Development, Oxford University Press, 1987, pp.8, 44. 
بعد مـور نحو ثلاثة عقود على نشوء فكرة الاستدامة؛ أنبّا نلحظ تدهوراً في الأنظمة

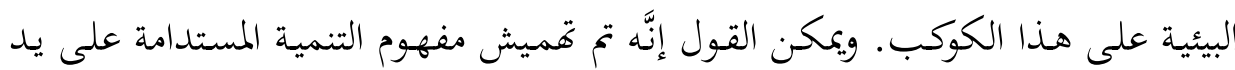

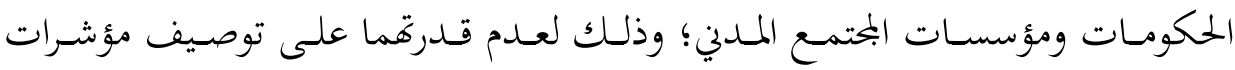

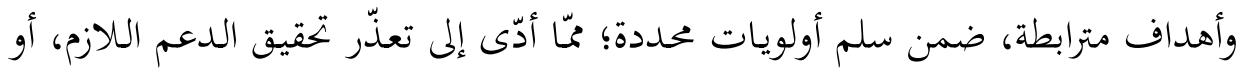

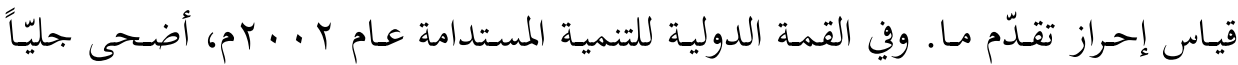
مدى عدم توفر الزخم الكافي لتحريك دفة التنمية المستدامة وتوجيهها نحو مسار محدد

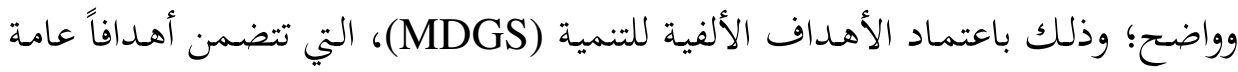

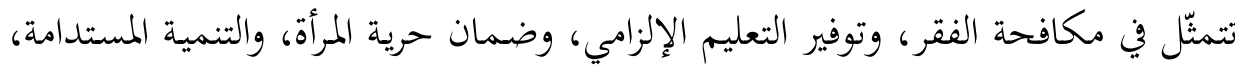

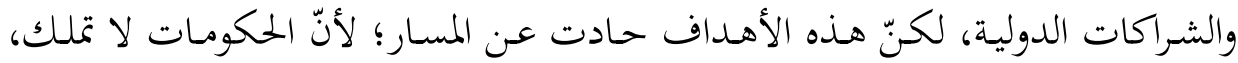
عمليّاً، القدرة والإمكانيات اللازمة للتحكّم في النتائج.

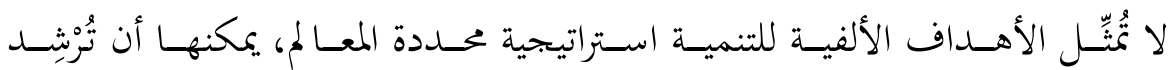

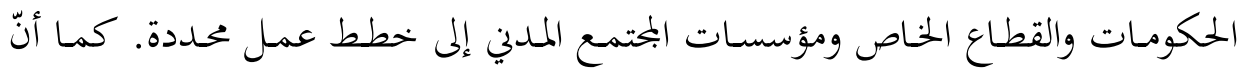
معظم مـا تتضمنه هذه الأهداف يعكس عملية دبلوماسية، كانت مكرّسة لوضع قائمة

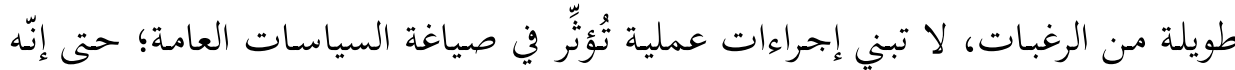
لم يُنَر أيّ مـن الأسئلة الجوهريـة، من مثل: أين يمكن استثمار المبالغ التي يوفرها الدهاعم الخـارجي؟ هـل يكـون ذلـك في قطساع الميـاه والصـرف الصـحي، أو لتصـحيح المســار الاقتصادي، أو معالجة معوقات التنمية، مثل الفساد وغياب الحكم الرشيد؟

بدايةً، ينبغي إحراز بحاح وتقدّم لافت في بحال التنمية الاقتصادية خاصة في مكافحة

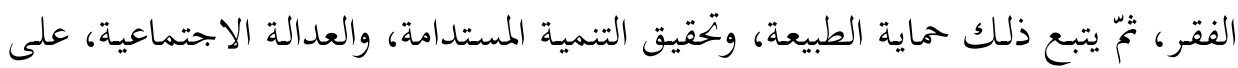
الرغم من التلازم والتناغم بين العناصر الثلاثة (الاقتصاد، والبيئة، والعدالة الاجتماعية).

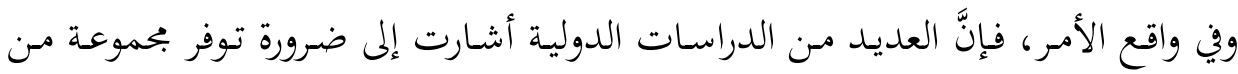

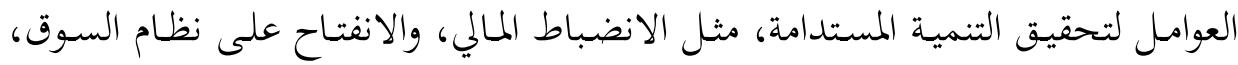

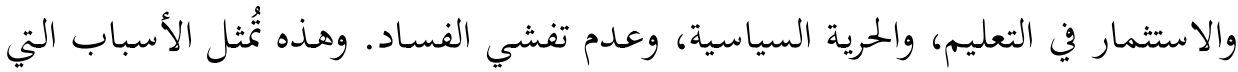

6 Fanelli, Daniele. World failing on sustainable development', New Scientist 2624: 03. 2007. 


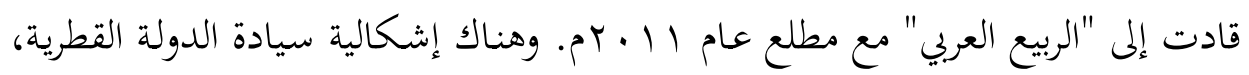

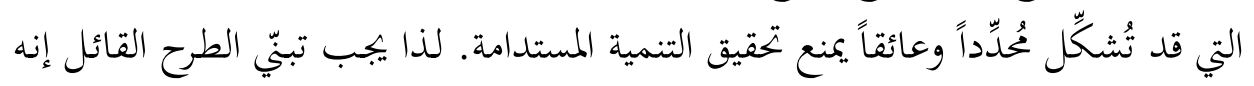

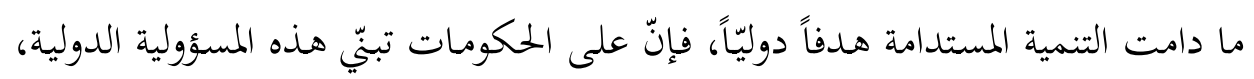

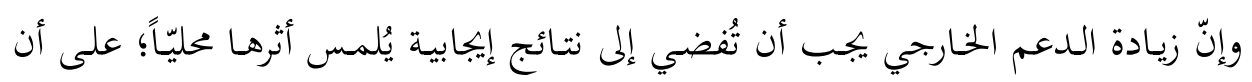

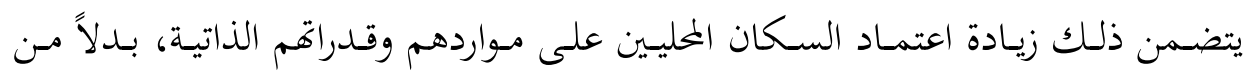
ترسيخ مبدأ التبعية للدول الكبرى، والاعتماد المتزايد على الدعم الخارجي.

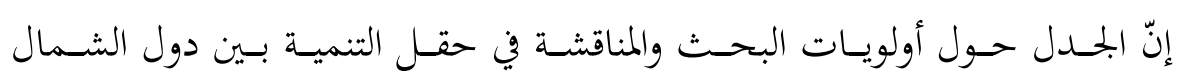

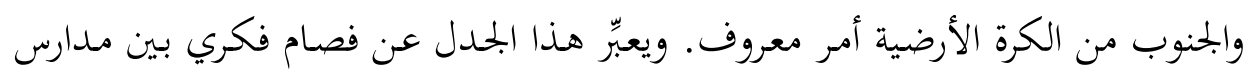

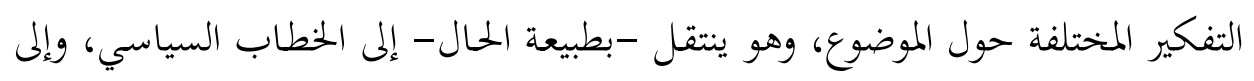

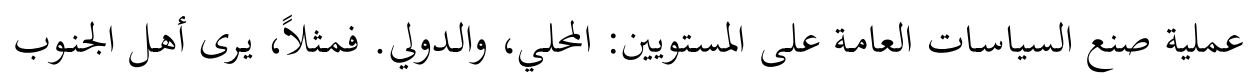

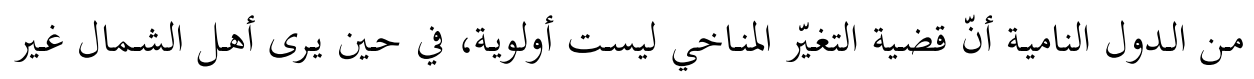

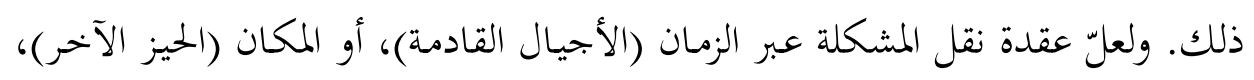

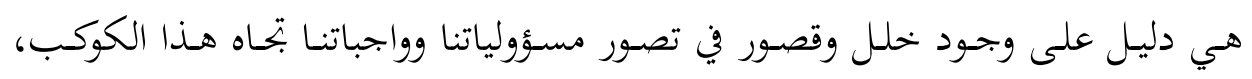

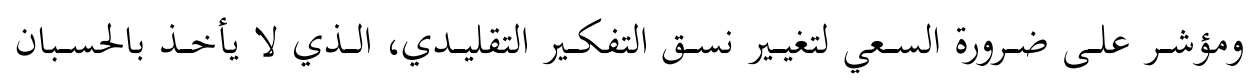

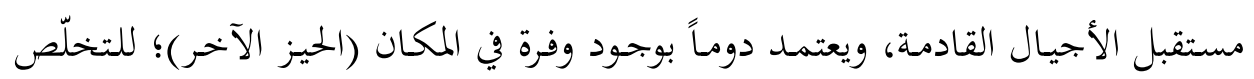

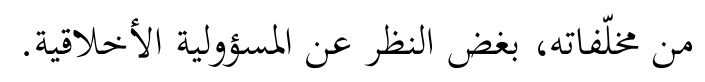

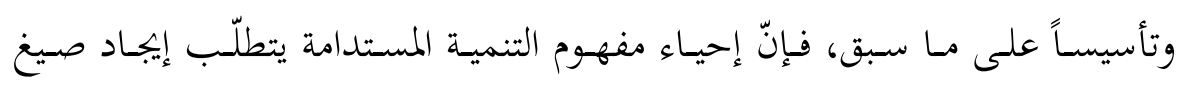

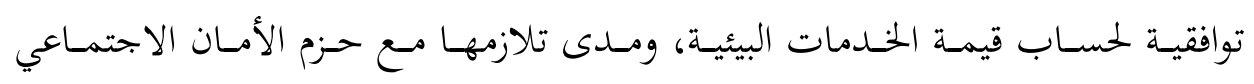

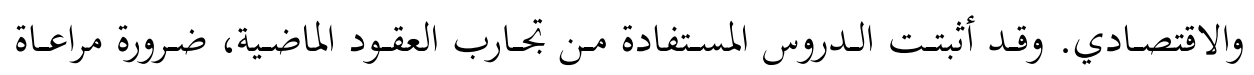

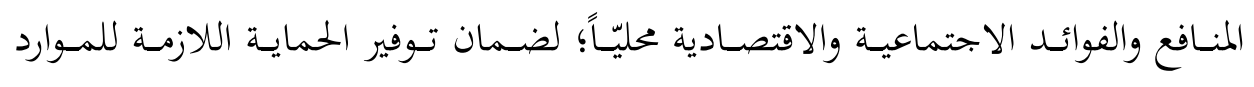

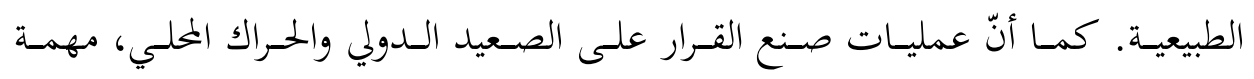

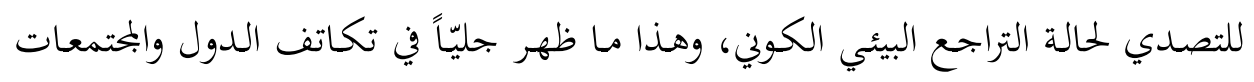

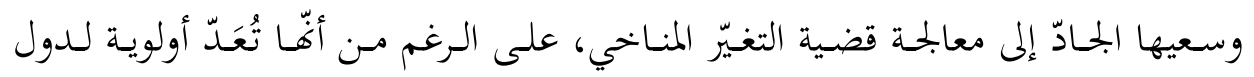

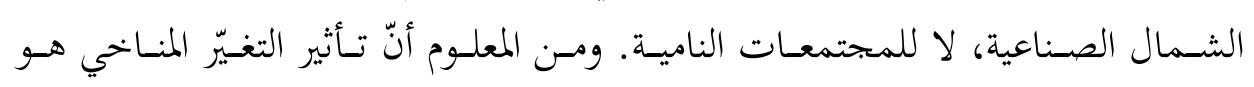




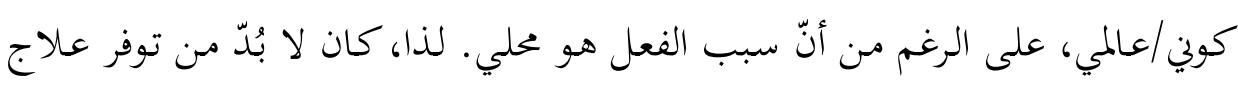
ناجح على الصعيد المحلي.

وخلاصة القول: إنّ عملية إحياء التنمية المستدامة تتطلّب تغييراً في نسق تفكير

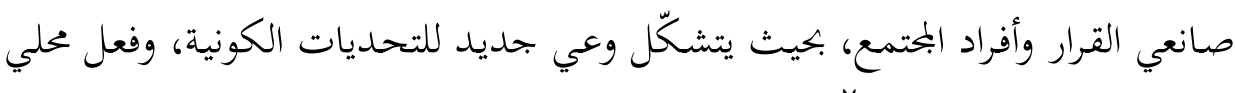

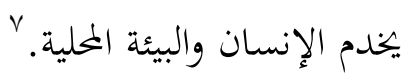

\section{أولاً: إنكالية التنمية المستدامة في الفكر الغربي}

تم التطرّق إلى إشكالية المحدودية البيئية (Environmental limits) في مطلع القرن

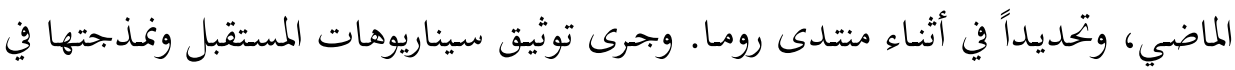

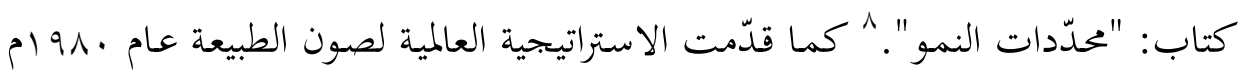

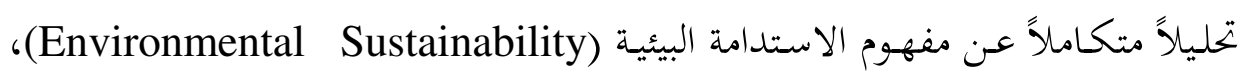
ركّزت فيه على ضرورة الحفاظ على العمليات الإيكولوجية والأنظمة البيئية، وإيلائها أهمية

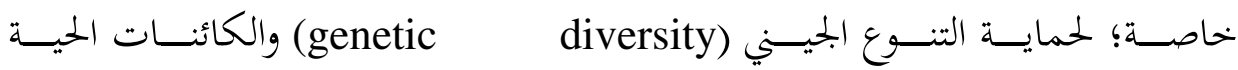

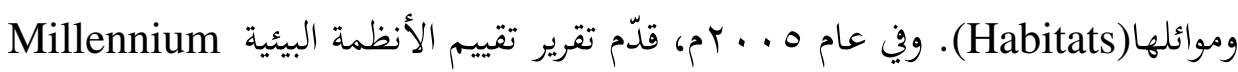
Ecosystem Assessment على النحو الآتي:

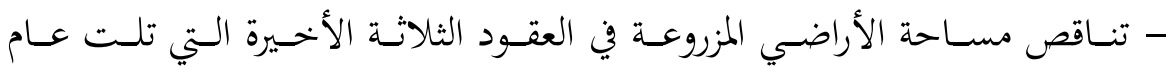

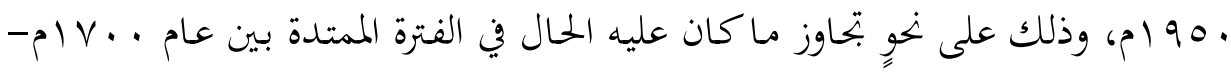
. 110 .

$$
\text { - نقص نسبتة . r\% في الشعاب المرجانية في الفترة الأخيرة. }
$$

${ }^{7}$ Korten D. C. When Corporations Rule the World. Berrett-Koehler Publishers, Kumaian Press, 1995. P.307- 333.

${ }^{8}$ Meadows, D. et al. The Limits to Growth. NY: Macmillan's, 1979.

${ }^{9}$ Millennium Ecosystem Assessment (MEA). Ecosystems and Human Wellbeing. Synthesis. Washington, DC: Island Press, 2005. 
- تضاعف استخدام مياه البحار والمخيطات منذ عام ـ 97 ام.

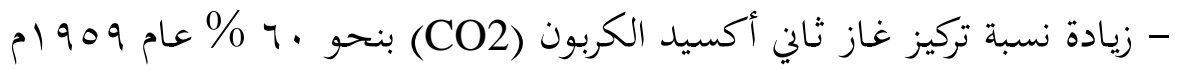

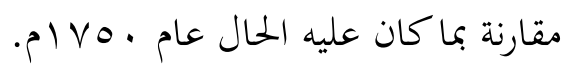

وقد بيّن التقرير أيضاً مدىى التباين بين دول الشمال والجنوب، ومددى اتساع دائرة

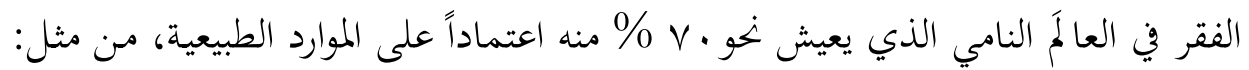

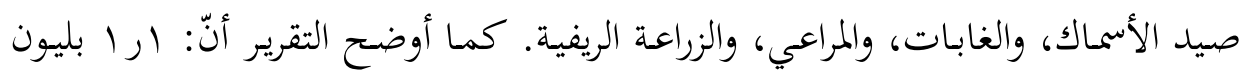

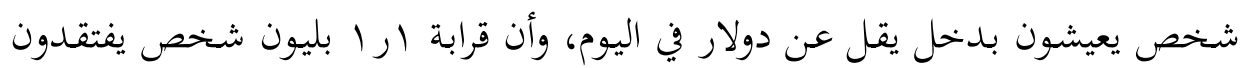

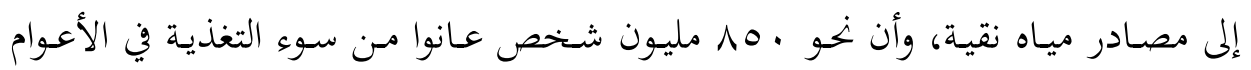

$$
\cdot(\rho r+r-r \cdot \cdots)
$$

لقـــ شـهـ القـرن العشـرون جــلاً واسعاً حـول الأثر السـلبي لـنمط التنميـة الغربي،

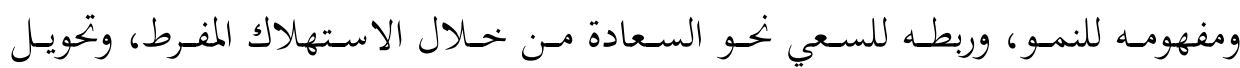

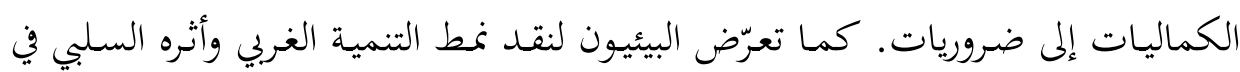

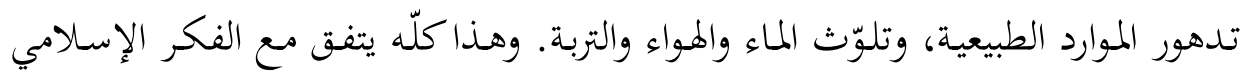

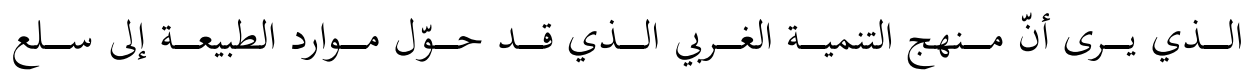

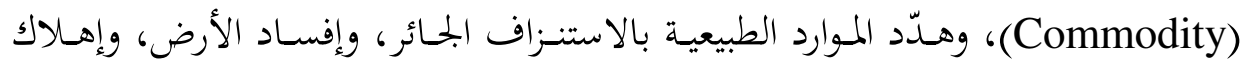

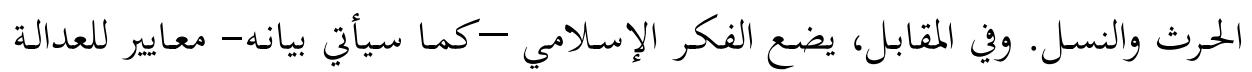

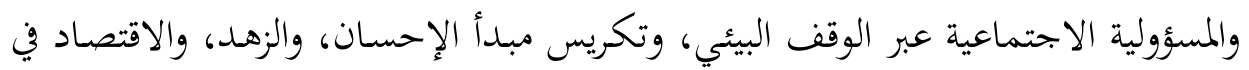

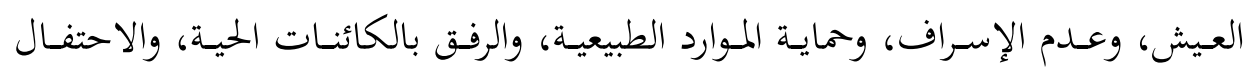
بالتنوع في الحياة.

والآن، ونحن في بداية القرن الحادي والعشرين، فإنّا نشهد نموّاً متصاعداً لدول آسيا،

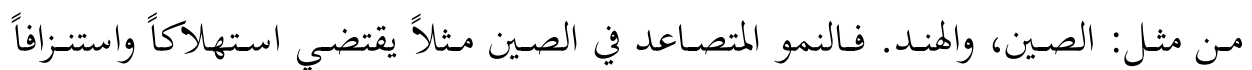

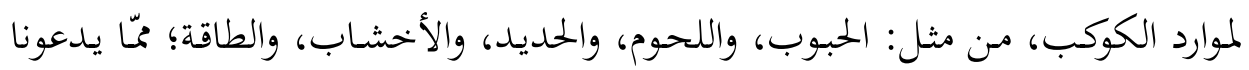

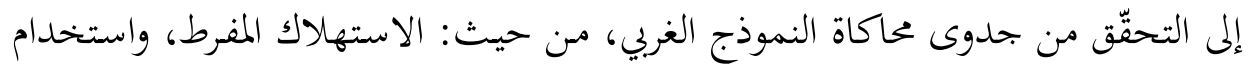

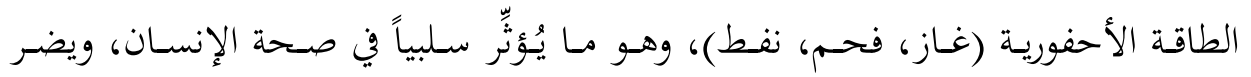


بالكوكب والاقتصاد. لذا، كان لا بُدّ من مراجعة نقدية لنمط التنمية الغربي، الذي فشل

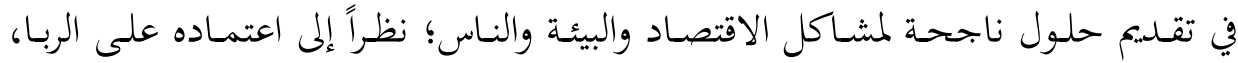

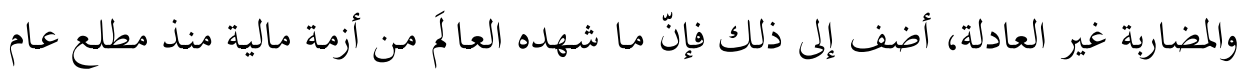

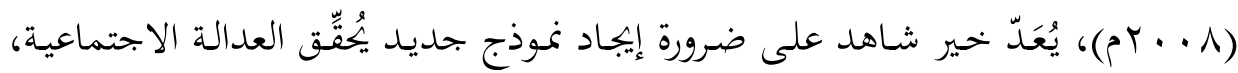

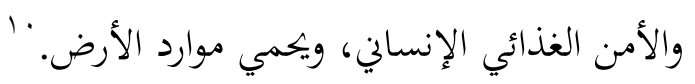
ولعلّ خير دليل على مدى فشل النموذج الغربي في تحقيق العدالة الاجتماعية، هو

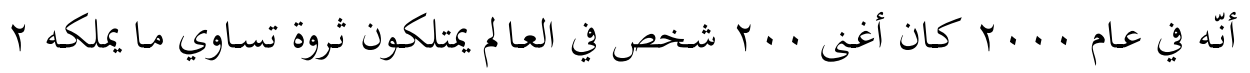

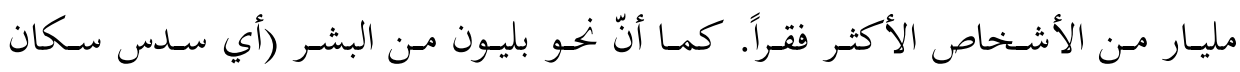

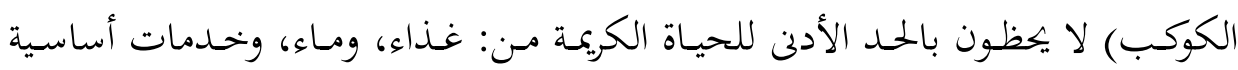

$$
\text { من: تعليم، ومرافق صحية. 'ل }
$$

إنّ المظــاهر والنتـائج المترتّــة علـى تبـنيّ نسـق التنميـة والتفكـير الغـبيين في العقـود

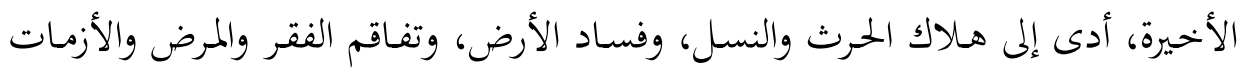

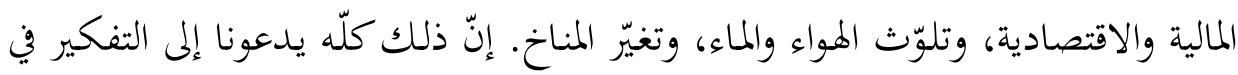

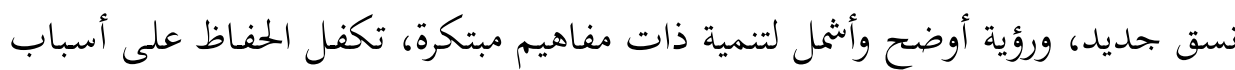

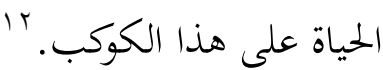

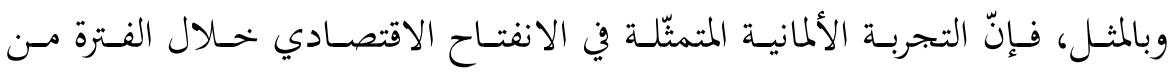

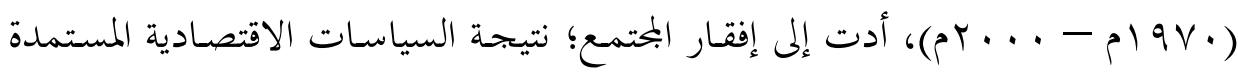

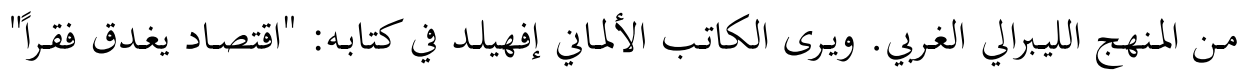

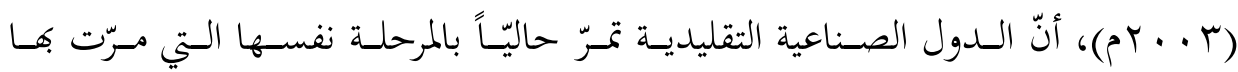
الأرجنتين والعديد من دول أمريكا الجنوبية في مطلع عصر النهضة الصناعية، والهند إبان إندان

${ }^{10}$ Al-Jayyousi, Odeh. The State of Ecosystems and Progress of Societies, In:OECD, Statistics, Knowledge and Policy. Measuring and fostering the progress of societies, 2008, pp. 441-451.

${ }^{11}$ Sachs, J. End of Poverty. New York: Penguin Press, 2005, pp. 26-30.

${ }^{12}$ Schumacher, E.F. Small is Beautiful: Economics as if People Mattered. NY, USA, Harbor and Row, 1973. P. 187- 193. 
حقبـة الاسـتعمار البريطـاني؛ إذ دمـرت حريـة التجـارة العالميـة الصـناعة في هـذه البلـدان،

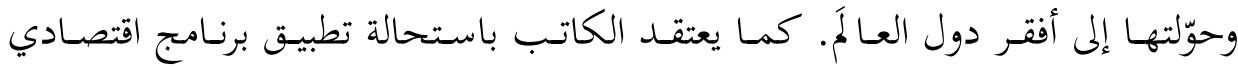

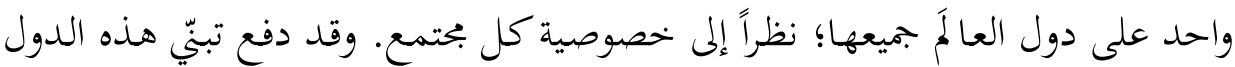

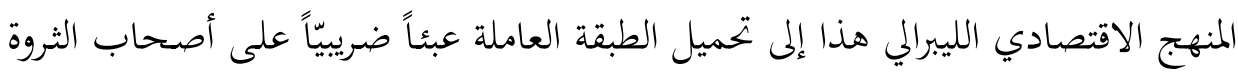

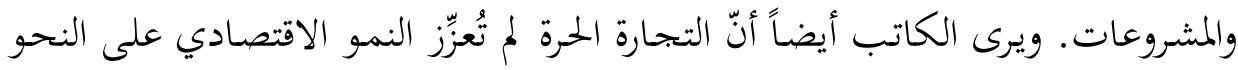

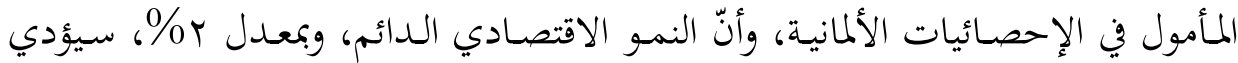

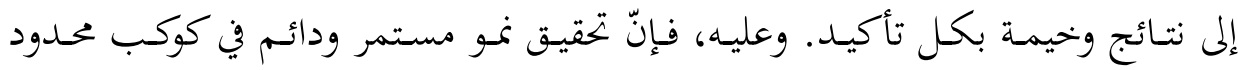

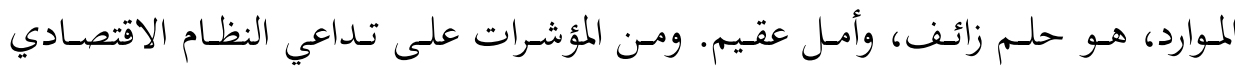
الليبرالي، تناقص معدل حصة الفرد الواحد من الناتج العالمي، بحيث فقدات نصفي ونف قيمتها إبان الحقبة الليبرالية في ألمانيا.

تعّرض مفهوم التنميـة المستـدامة لموجـة مـن الانتقـادات، كـان منها صعوبة تحديـد

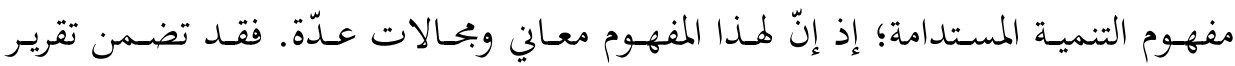
"مستقبلنا المشترك" صياغة للبُعْد البيئي (الإيكولوجي)، وضمّه إلى البُعْدين: الاقتصادي، والسياسي. وين قمـة (ريـو)، تمّ التركيـز على التغسيرّات البيئيـة الكونيـة؛ ومشـاكل تنـوع الأحياء، وشح الموارد وتدهورها، والتغيّر المناخي. أمّا في القمة الدولية للتنمية المستدامة

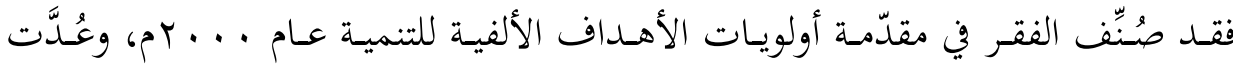
الاستدامة أحد الأهداف الثمانية التي يقاس بها مدى التقدّم في حياة الناس. من جانب آخر، يرى بعض الخبراء أنّ أحد الأسباب التي أدت إلى انتشار فكرة الاستدامة، تكمن

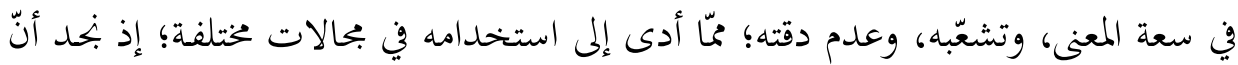
رجـال السياسـة، وصـنّاع القـرار، ورجـال الأعمـال، وخـبراء التنميـة والاقتصـاد، والمجتمـع المدني، كلّهم يستخدمون هذا المفهوم (التنمية المستدامة). ولكن، لكالٍٍ منهم رؤى مختلفة في ما يخص تناغم الاقتصاد مع البيئة. لذا، نجد أنّ مفهوم التنمية المستدامة قد يؤدي إلى لى

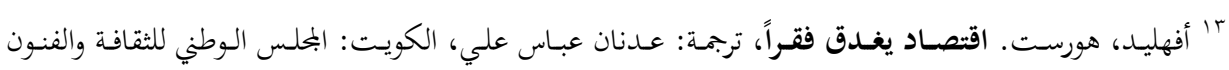

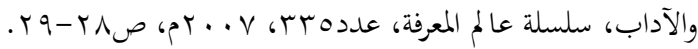


اجتماع الناس حول الفكرة نفسها، ولكنّه لا يُفضي بالضرورة إلى تفاهم حول الأهداف المنشودة.

ومسن أوجـه النقد التي وجهـت لمفهوم التنمية المستدامة كذلك، أنّ الأمـر لا يقتصر على صعوبة تحديد مفهوم التنمية المستدامة فحسب، بل في صعوبة تطبيق فكرة التنمية

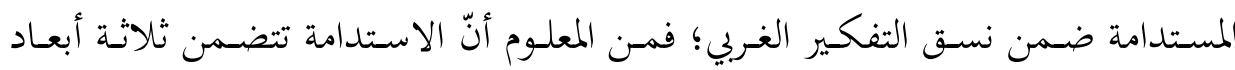

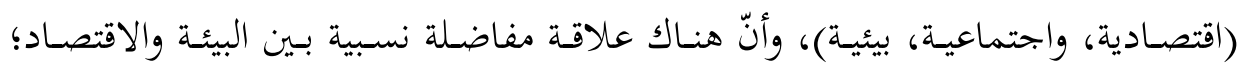

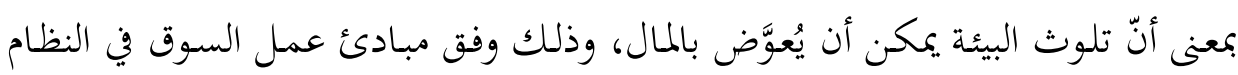

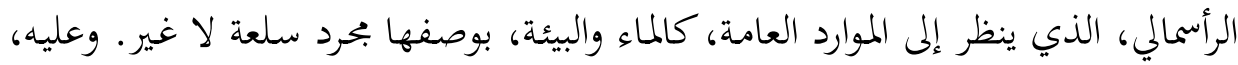
فقـد استُخدم مصطلح رأس المال الطبيعي (Natural Capital) لبيـان عناصـر النظام

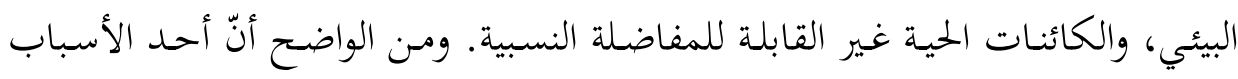

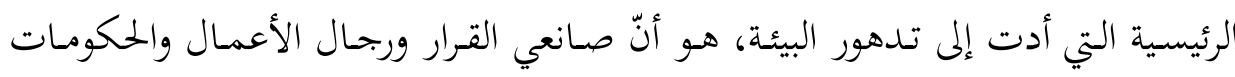

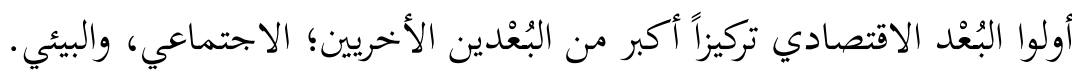
إنّ الأبعاد الثلاثة (الاقتصادية، والاجتماعية، والبيئية)، لا يمكن النظر إليها على أهـا

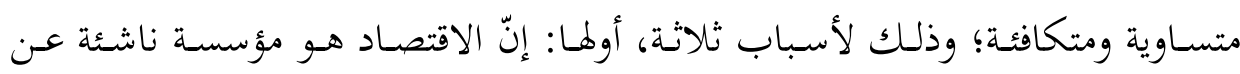

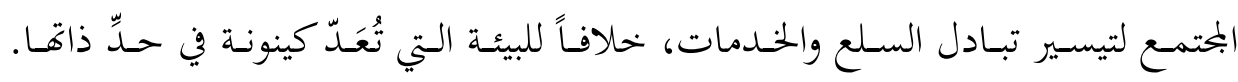

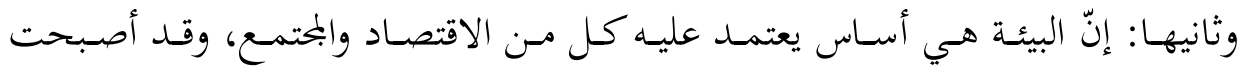

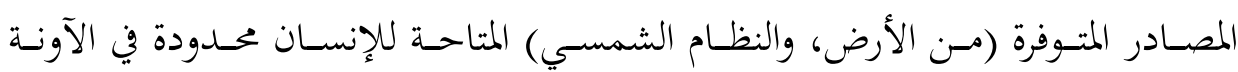

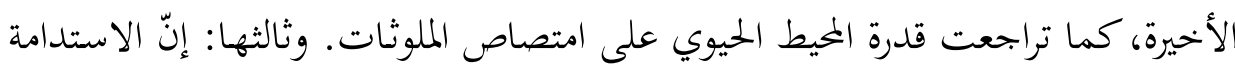

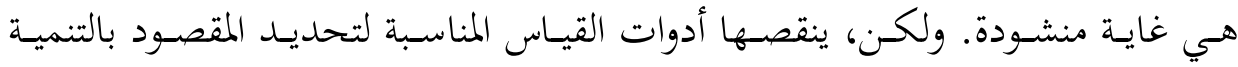

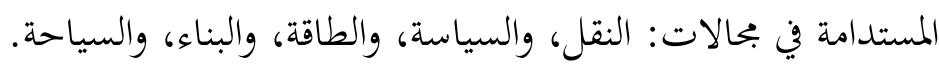

وعلى العموم، توجـد ثلاثة محاور لنقــ الاقتصـاد الغربي؛ وهي: الطاقة الاستيعابية

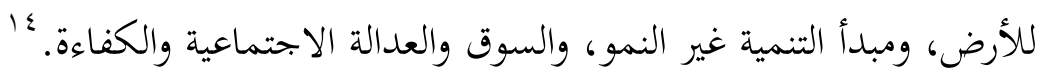

14 World watch Institute. State of the World 2008: Innovations for a Sustainable Economy, Washington: WWI, 2008, p.12- 25. 


\section{ا ـ الطاقة الاستيعابية للأرض:}

مُّّا لا شكّ فيه أنّ رؤية الغرب ونظرته إلى الأرض، هي أحد أسباب المشكلة البيئية التي نحياهـا اليوم؛ إذ سيطرت عليه فكرة أنّ الأرض هي مصدر لا ينضب، يمكنه تزويد

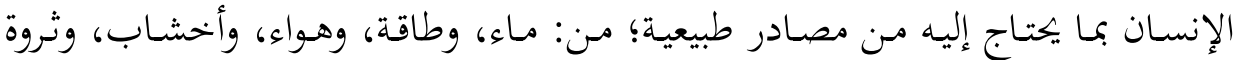
حيوانيـة وسمكيـة. كمـا سـاد اعتقـاد، منـذ بـده عهـد الاكتشـافات العلميـة مطلع القـرن التاسع عشر، بأنّ الكون يعمل ضمن قوانين فيزيائية، وأنّ بمقدور الإنسان أن يتحكّم في الكون، ويصنع كل ما يحتاج إليه من مواد ولوازم. 10

ولكن، لم يدرك الإنسان مـدى قدرة الأرض على التحِّمل، واستيعاب مخلّفاته مـن الصناعة، ناهيك عن النمو المتصاعد الوتيرة في مختلف ميادين الحياة. ومع ارتياد الإنسان

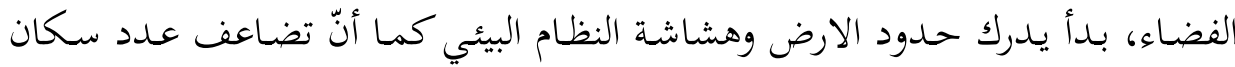

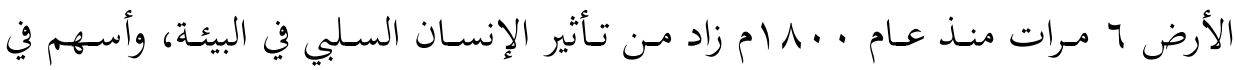

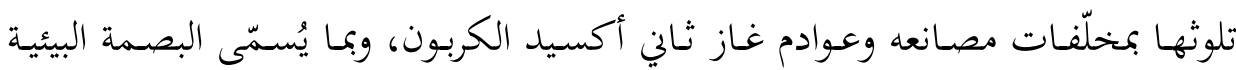

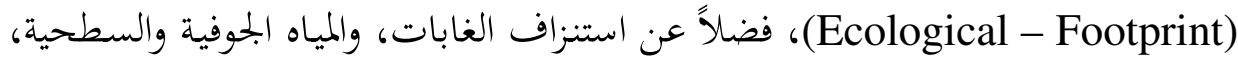
والثروة السمكية في البحار والمحيطات. 17

إنّ هذا الاستنزاف لرأس المال الطبيعي نتيجة النمو اللامتناهي، والنمو لأجل النمو،

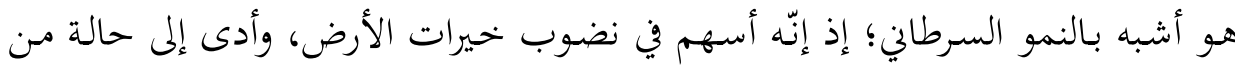

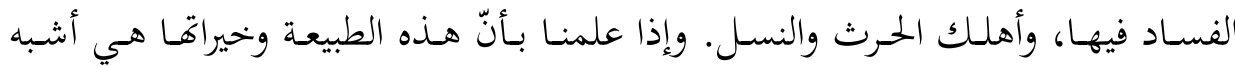

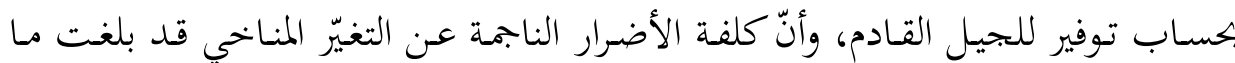

15 Meadows, D. Beyond the Limits. Confronting Global Collapse. Vermont: Chelsen, Green. 1993, P.21- 36.

${ }^{16}$ Ward, B. Spaceship Earth, New York: University of Columbia Press, 1999. See also:

- Boulding, Kenneth E. 'The economics of the coming spaceship earth', in H. Jarrett (ed), Environmental Quality in a Growing Economy, Baltimore, MD: Resources for the Future/Johns Hopkins University Press, pp. 3-14. 


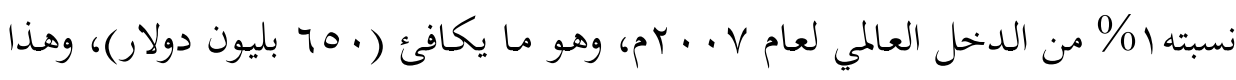

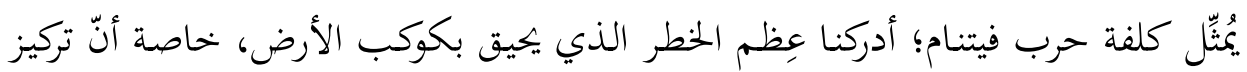

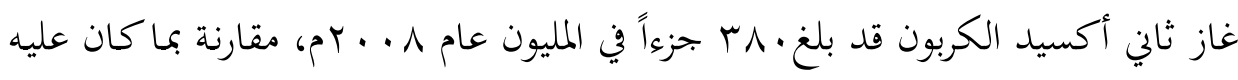

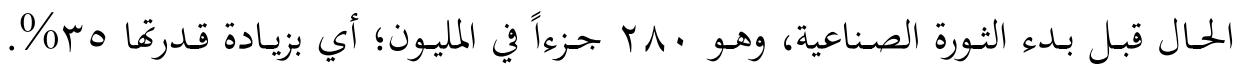

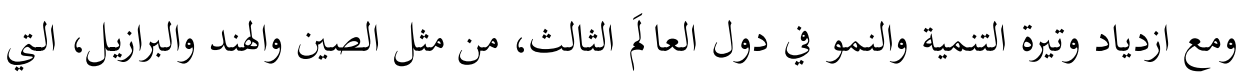

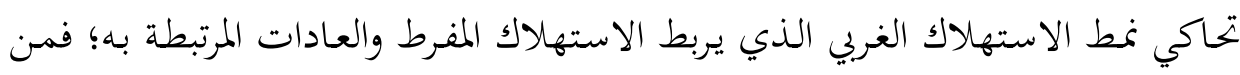

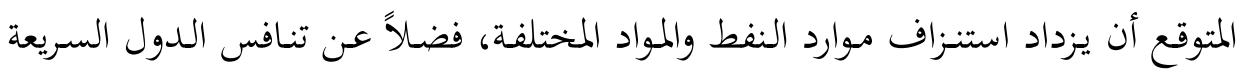

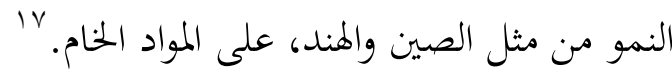

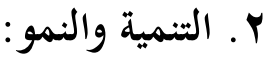

مـن المهم هنـا بيان الفرق بين التنمية والنمو؛ فالنمو يرنو إلى جعل الأشياء أكبر،

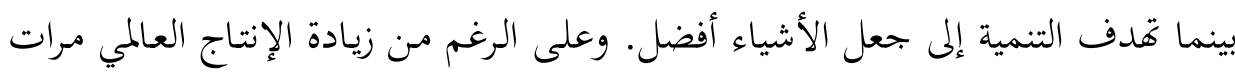

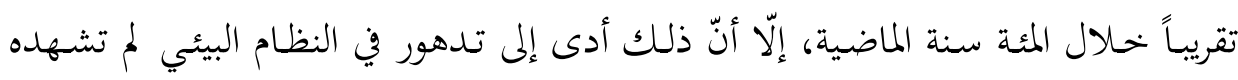

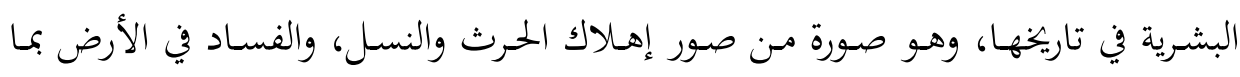

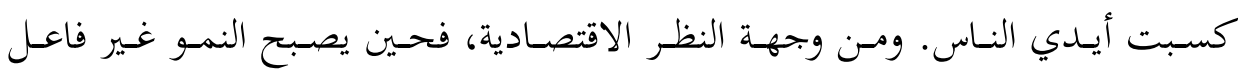

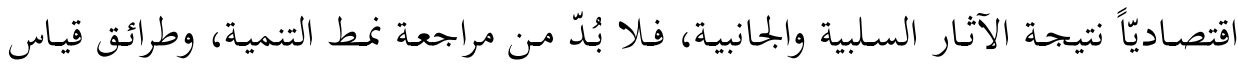

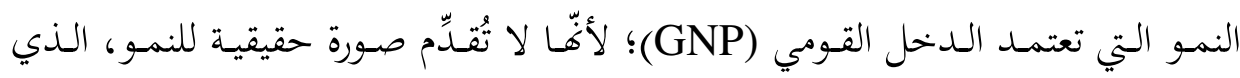

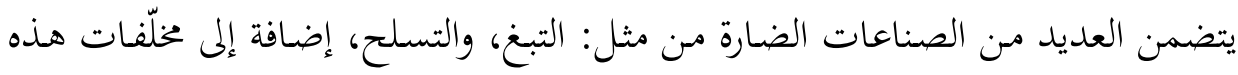

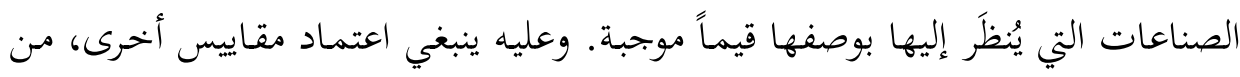

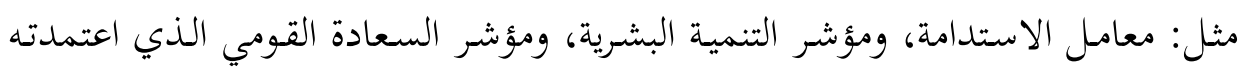

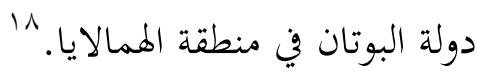

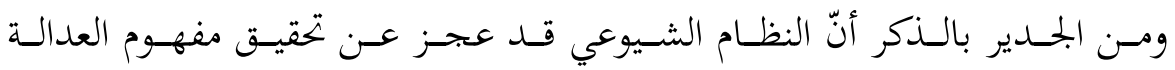
الاجتماعية، مثلما عجز النظام الرأسمالي الحالي عن المحافظة على النظام البيئي لأنه يعتمد ${ }^{17}$ Hussain, Muzaamal. (2007). Islam and Climate Change: Perspectives and Engagements. Page. 6-7. www.lineonweb.org.uk/Resources/reading/ ${ }^{18}$ Al- Jayyousi, Odeh. The State of Ecosystems, op cit. pp. 441-451. 


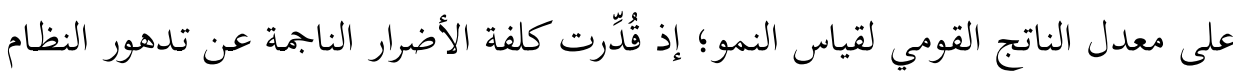

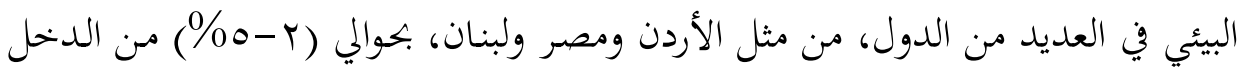

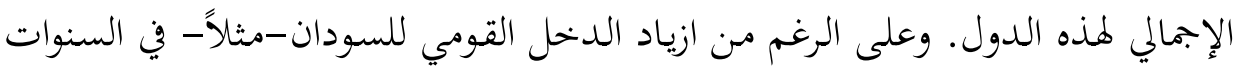

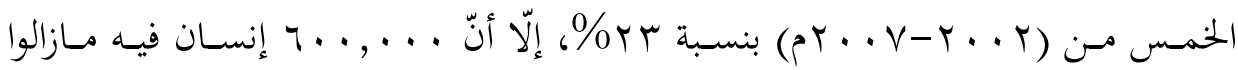

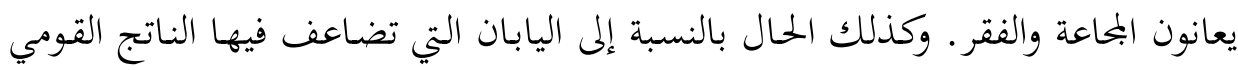

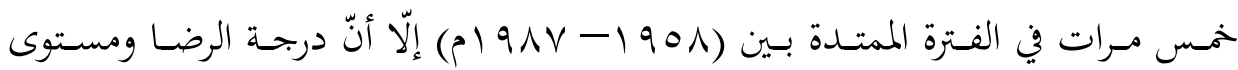

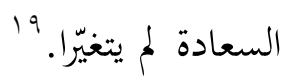

\section{r. السوق والعدالة الاجتماعية والكفاءة:}

تقوم النظرية الاقتصادية في النظام الرأسمالي على مبدأ أنّ السوق هي أكثر كفاءة في

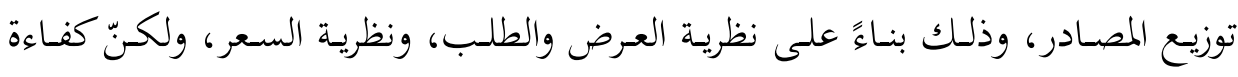

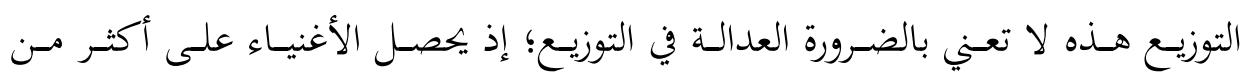

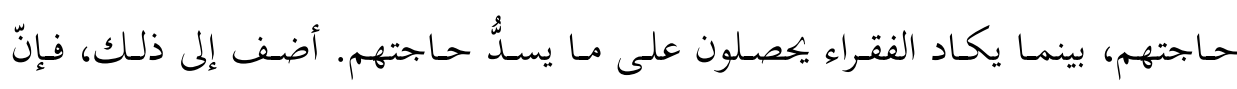
السوق تتجاهل قيمة الثروات الطبيعية البيئية وما تقدّمه لنا من منافع جمّة، فعلى سبيل

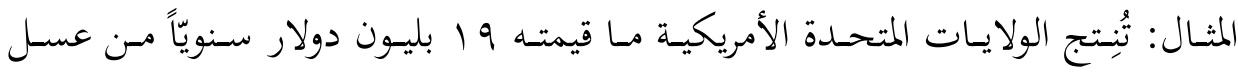

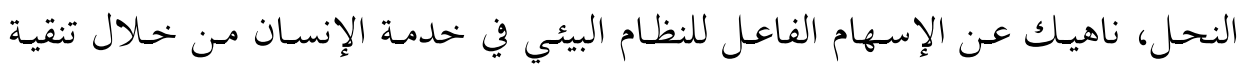

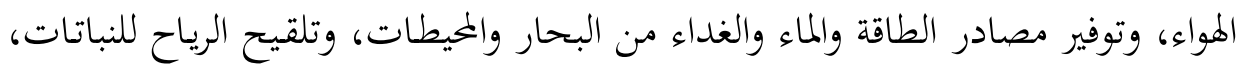

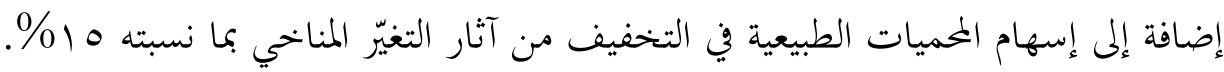

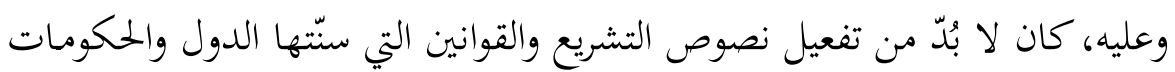

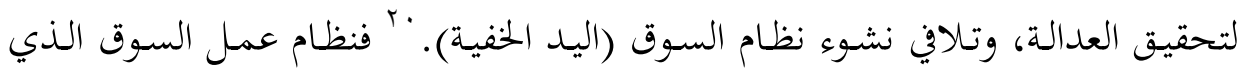

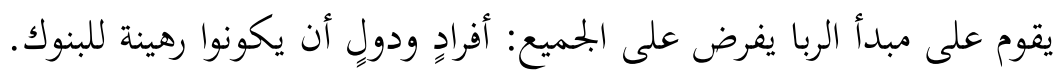

${ }^{19}$ Yunus, M. Creating a World without Poverty. NY: Public Affairs, 2008, p.118-131.

${ }^{20}$ Smith, A. The Wealth of Nations. NY: Penguin, 2003, p.25-88. 


\section{ثانياً: إشكاليات الفكر الغربي بين مركزية الثقافة والطبيعة}

إنّ المتأمل في التحديات البيئية الكونية، من مثل: ظاهرة التغيّر المناخي (الاحتباس

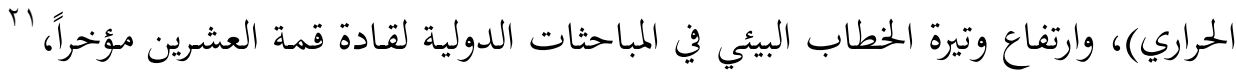

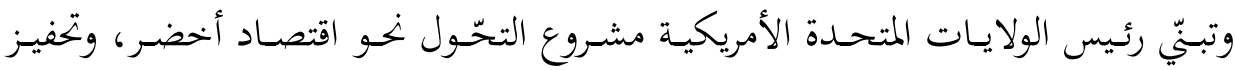

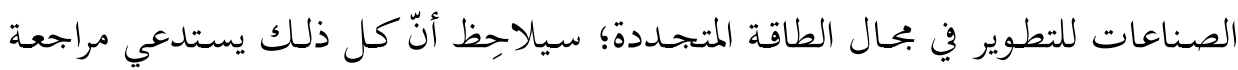
البناء المعريف وصوغه على نحوِ يُفضي إلى تطوير فكر بيئي جديد مرتبط بالثقافة العربية والإسلامية، فضلاً عن مراجعة الفلسفة العربية الإسلامية المتعلقة بالمعرفة والمعارف والعقل والعقلانية.

يرى بعض المعنيين بتحوّلات الفكر البيئي أنّ المذهب العقلي الذي يُعُدّد العقلانية

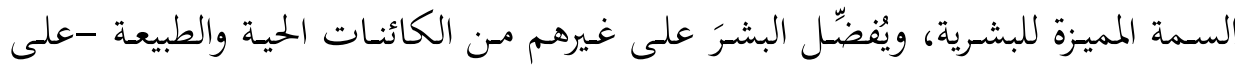

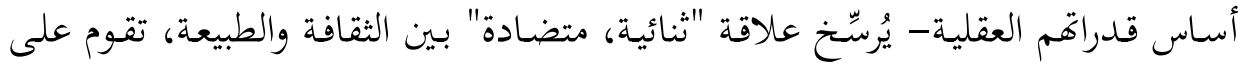

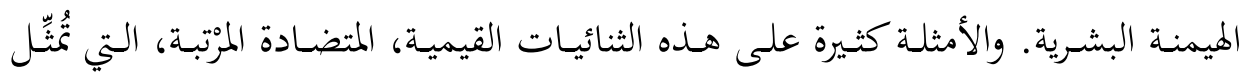
الانقسامات الآتية: الثقافة والطبيعة، الإنسان والطبيعة، العقل والعاطفة، الرجل والمرأة،

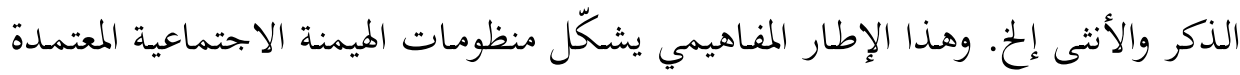

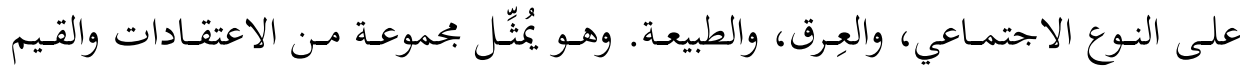
والمعارف والافتراضات التي تعكس رؤية المرء لنفسه وعالمه. ويكون هذا الإطار جائزاً حين الإني

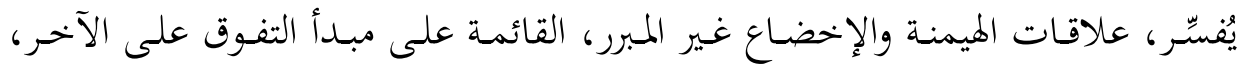

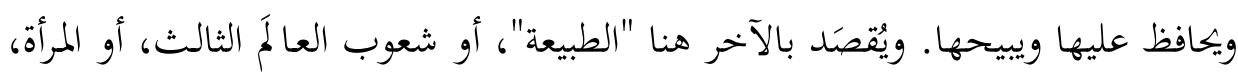

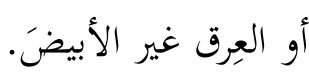

وفي واقع الأمر، فإنّ الفكر الغربي يمثّل الطبيعة في صورتين مستمدتين من النظرة

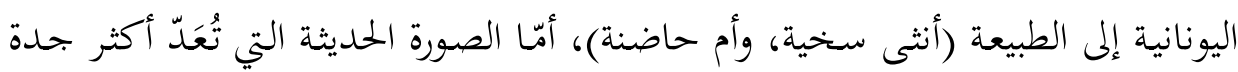




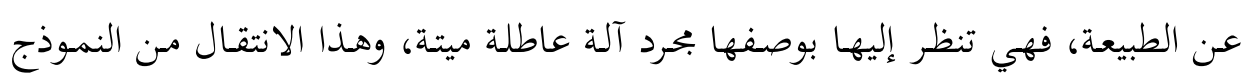

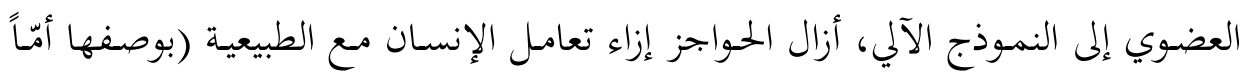
حيةً).

\section{المدارس الثقافية السياسية للإيكولوجيا:" آم}

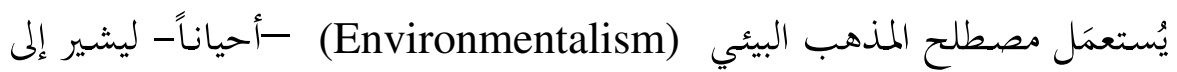

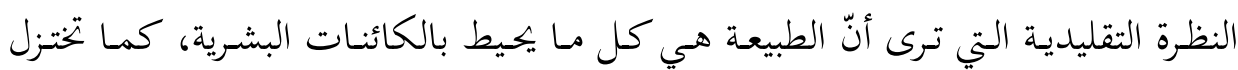

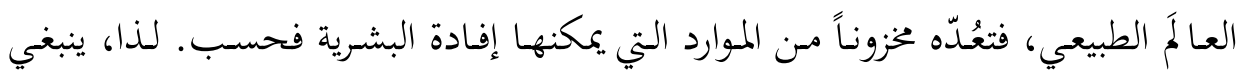

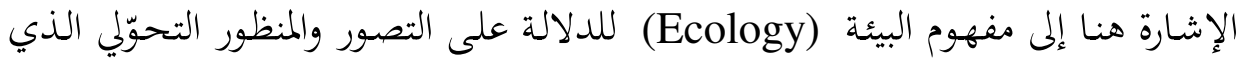

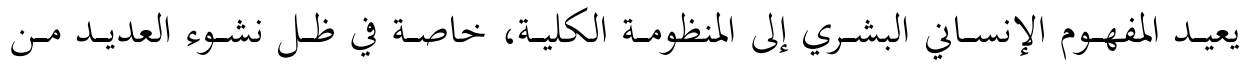

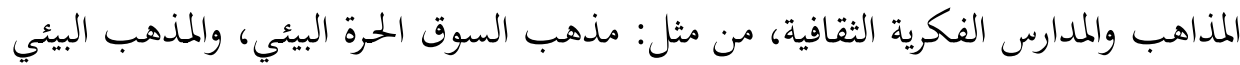
التقليدي المحافظ، ومذهب السوق الخضراء البيئي، والمذهب البيئي الليبرالي، والإيكولوجيا الاشتراكية، والإيكولوجيا الاجتماعية، والنسوية الإيكولوجية، والإقليمية الحيوية. وفيما لإيكا

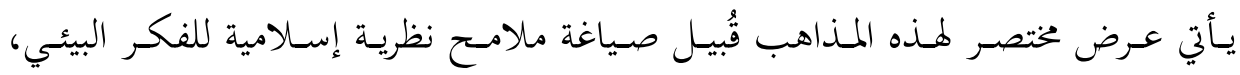

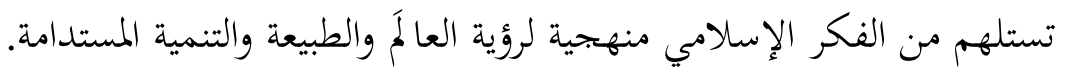

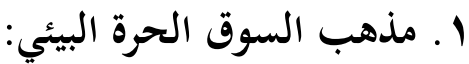

يعتمد هذا المذهب على المبدأ القائل إنّ العدالة والخير يمكن الوصول إليهما عبر

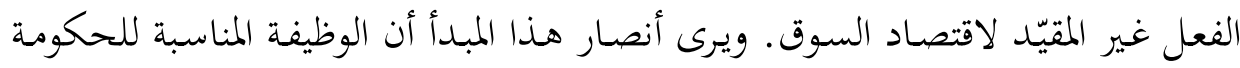

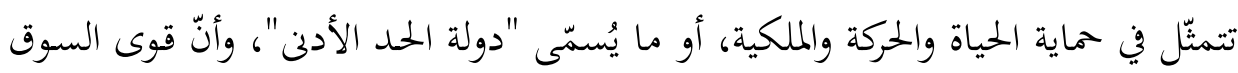

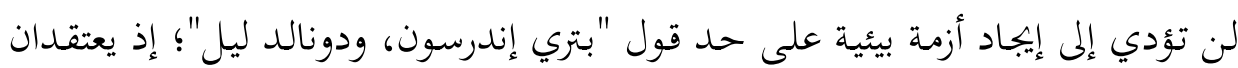

${ }^{22}$ Warren, Karen J. Eco-feminist Philosophy: A Western Perspective on What It Is and Why It Matters, Lanham, MD: Rowman \& Littlefield, 2000. p.15-23.

${ }^{23}$ Zimmerman, Michael E. (2001). Environmental Philosophy: From Animal Rights to Radical Ecology. Prentice Hall, $3^{\text {rd }}$ edition- N.J, U.S.A. 


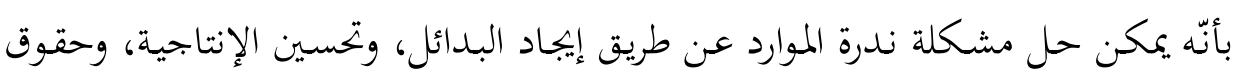

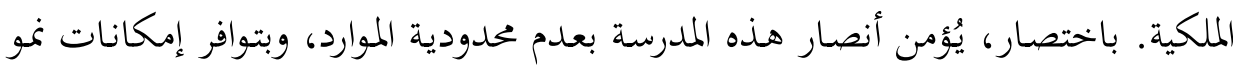

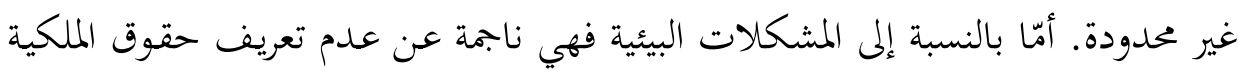

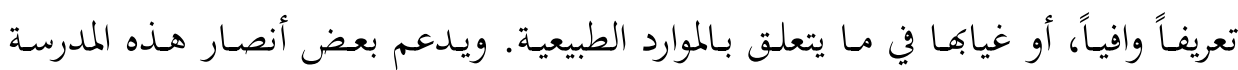

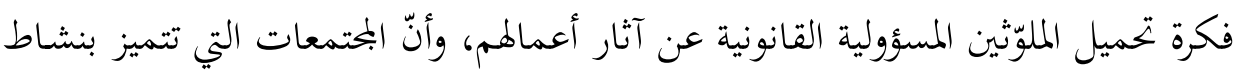

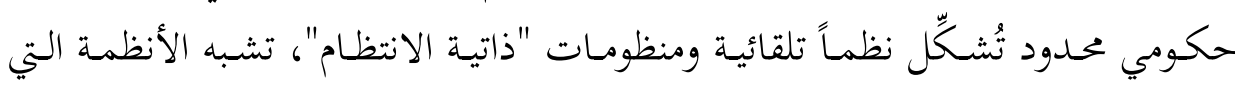
تعمل على نهوٍ طبيعي ودائم.

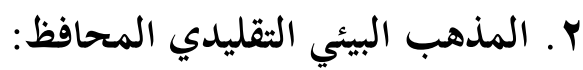

يقوم هذا المذهب على أعمال "آدم سميث، وجون لوك"، والليبرالية الكلاسيكية،

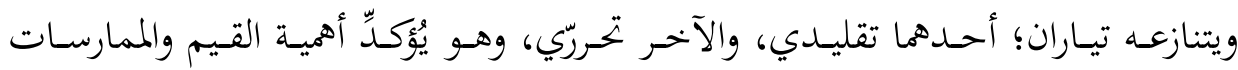

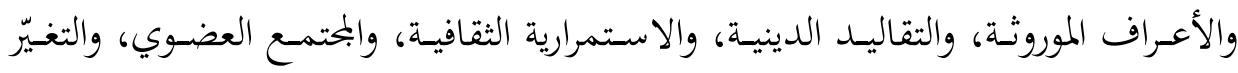
الاجتماعي، كما يُرِّز على المجتمع أكثر من تركيزه على الفرد.

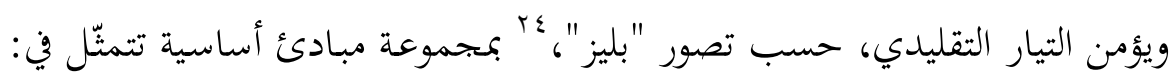

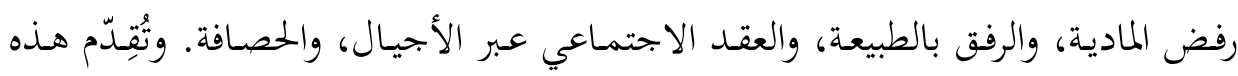

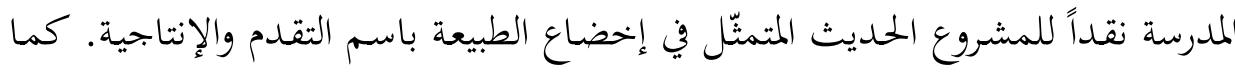

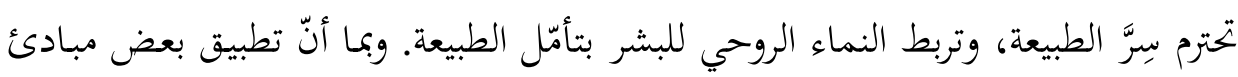
المدرسة -من مثل الرفق (empathy) والحصافة (efficacy)، على ظاهرة التغيّر المناخي

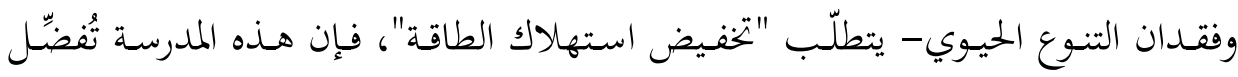

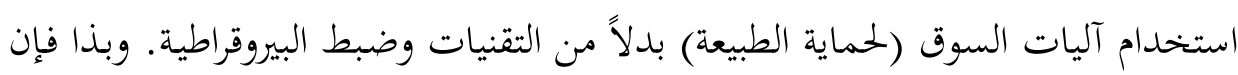

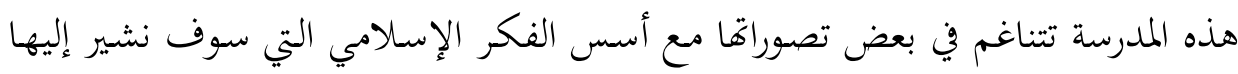

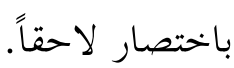

${ }^{24}$ Bliese, John. (1997). Traditionalist Conservation and Environmental Ethics, Environmental Ethics, 19 (2): pp. 135-151. 


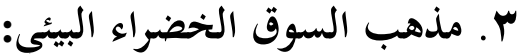

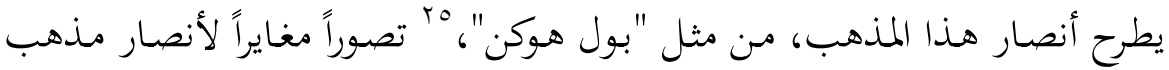

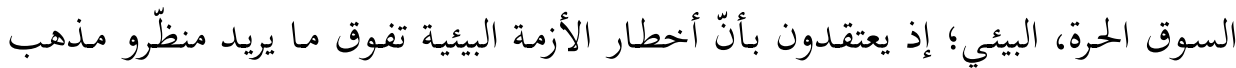

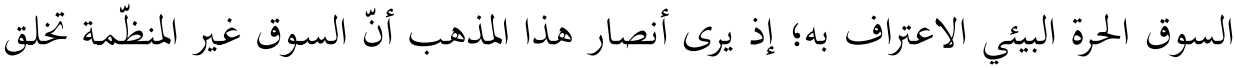

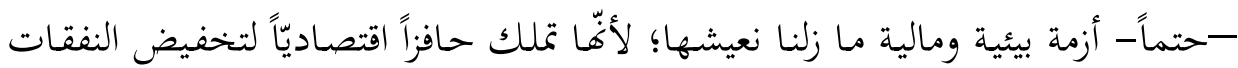

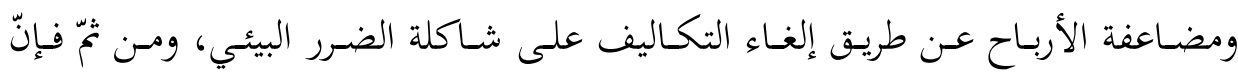

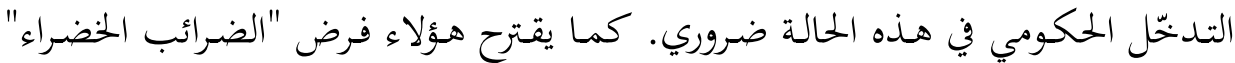

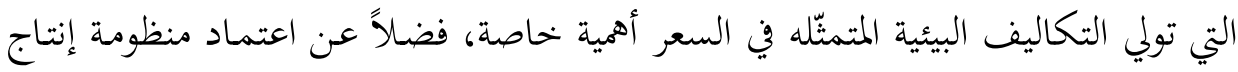

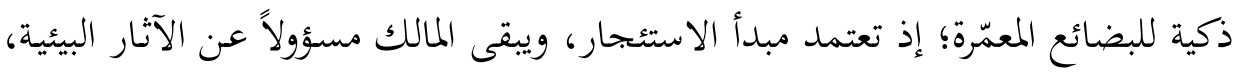

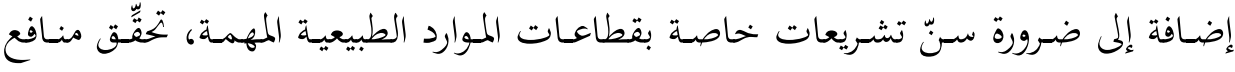
عامة، وتعمل وَفق مبادئ السوق، وتراعي الاستدامة.

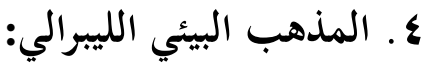

يرى أنصار هذا المذهب أنّ النشاط غير المقيّد للسوق لائ يستطيع حلّ المشكلات

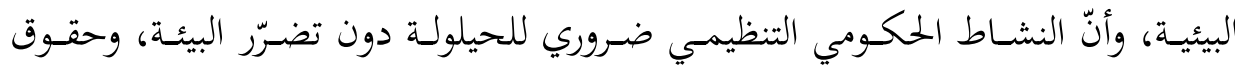

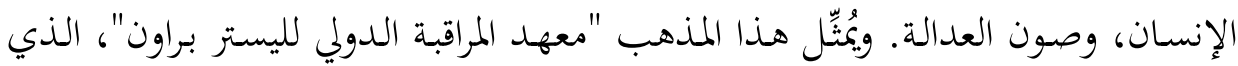

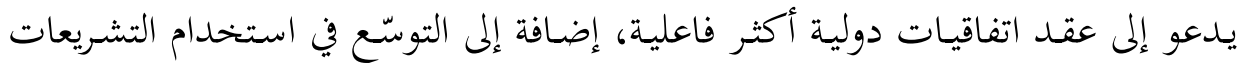

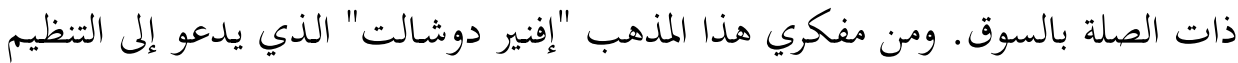

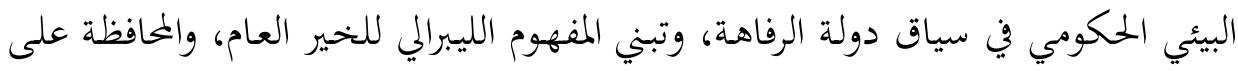

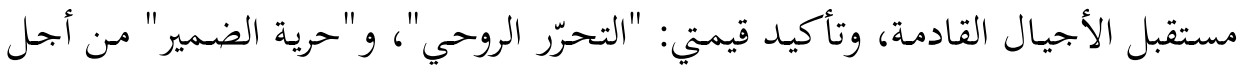

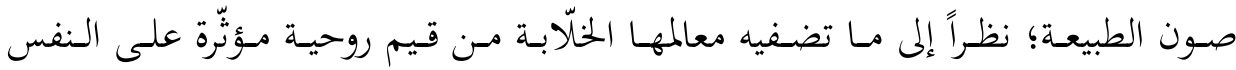

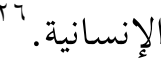

${ }^{25}$ Hawken, P., Lovins A. and Lovins L. Natural Capitalism, Colorado, USA: Rocky Mountains Institute, 1999, p. 23-37.

7" زئرمان، مايكل. الفلسفة البيئية، من حقوق الحيوان إلى الإيكولوجيا الجذرية، الكويت: البلس الوطني للثقافة

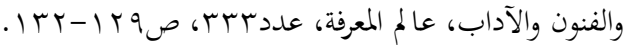




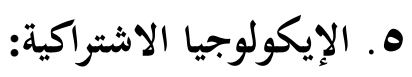

يُطبّق "جيمس أوكونور" فكرة التحليل الماركسي لشروط الإنتاج على القضايا البيئية،

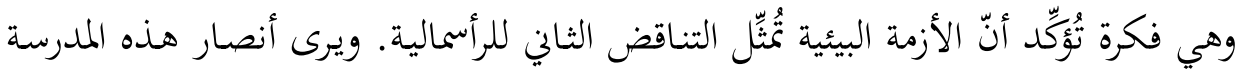

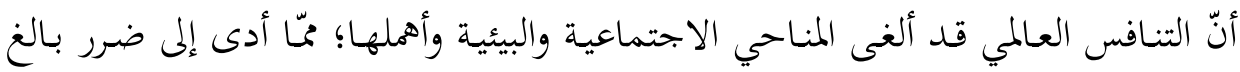

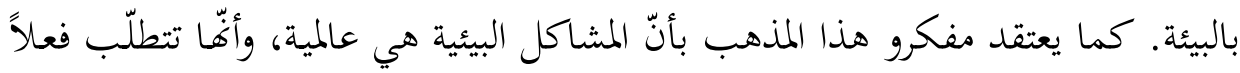

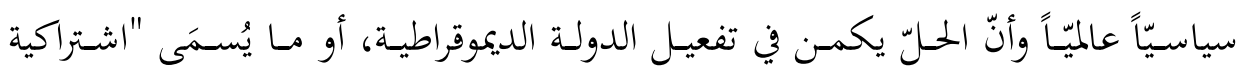

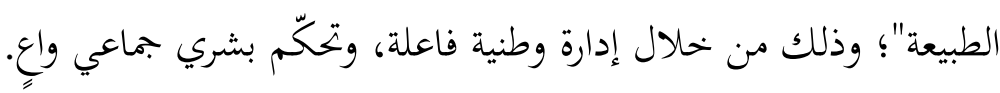

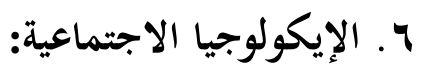

تنظر هذه المدرسة نظرة تطورية إلى التاريخ والاجتماع والسياسة، وتؤمن بأنّ مفهوم

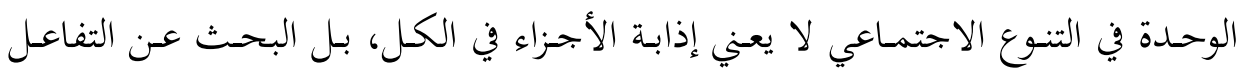

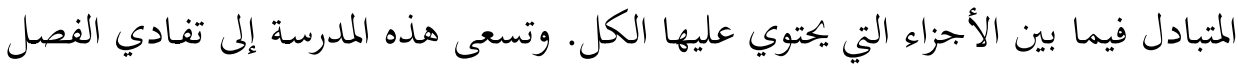

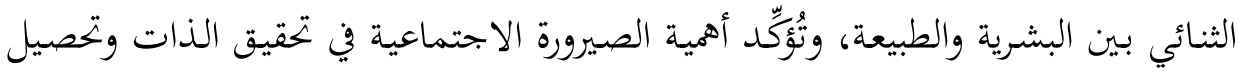

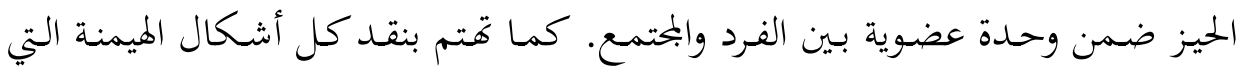

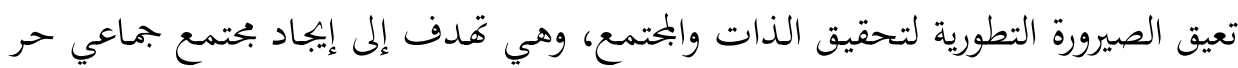

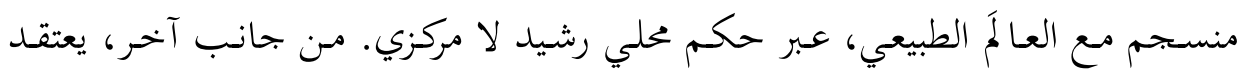

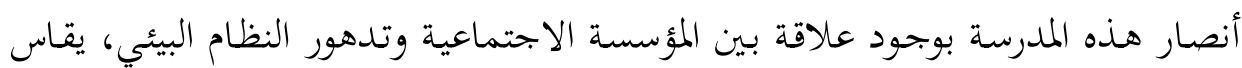

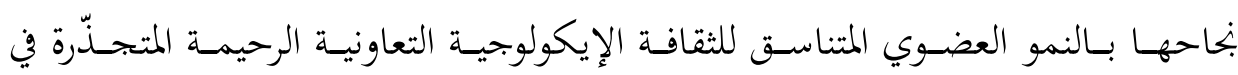
خصوصية التاريخ والمكان.

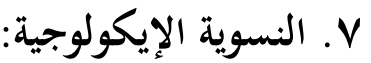

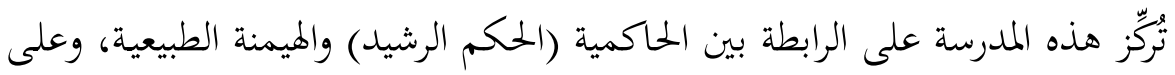

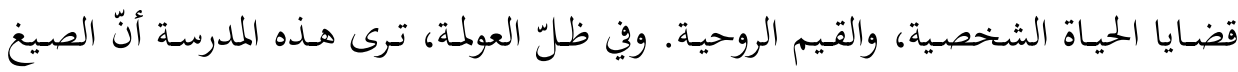

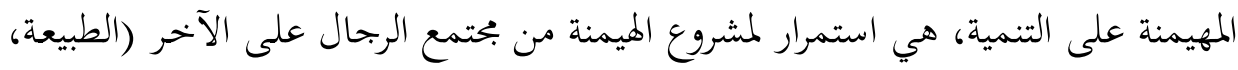

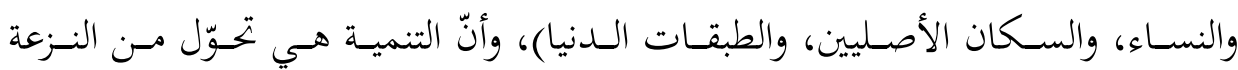


الاستعمارية الكلاسيكية، التي نفـذّت خططهـا عسبر الإخضـاع العسـكري والاحستلال

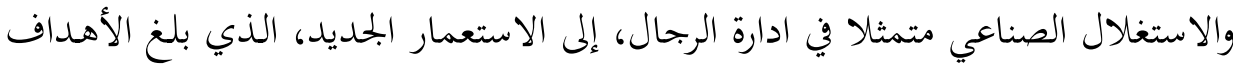
نفسها عبر النخـب الوطنية والنظم التقنية، بمـا في ذلك الثقافة، وطرائق الإنتاج المحلية، والتأثير السلبي في الطبيعة والتي يعبر عنها كأنثى.

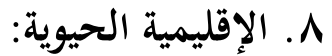

تُركّز الإقليميـة الحيويـة على ضـرورة إعـادة التوطين، وذلك بإيجـاد ثقافـة وطريقـة في

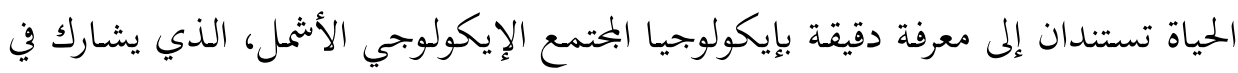

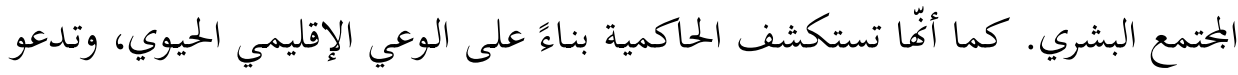

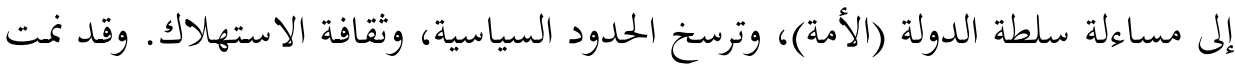

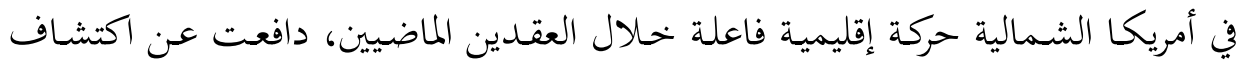

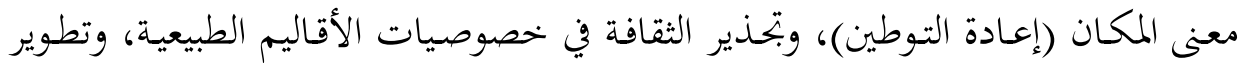

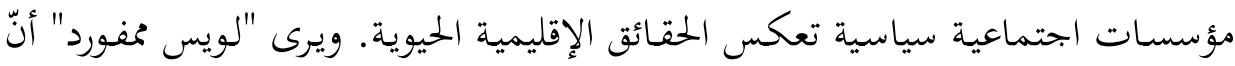

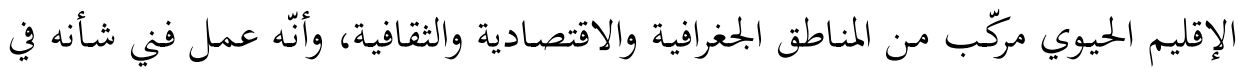

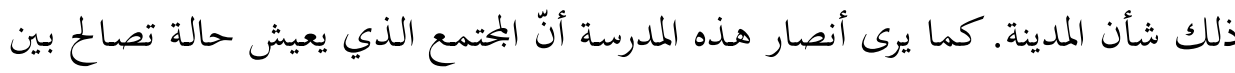

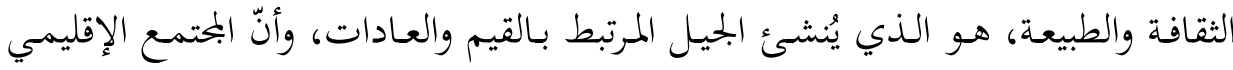
الحيوي اللا مركزي والديموقراطي سيكون المعادِل الاجتماعي للبيئة المستدامة. وهذه نظرة جديرة بالتأمّا؛ لإعادة صياغة إقليم حيوي عربي ضمن رؤية تنموية تربط قضايا: الغذاء، والماء، والطاقة، والتجارة ببعضها.

\section{ثالثاً: نحو نظرية إسلامية للتنمية الطيبة}

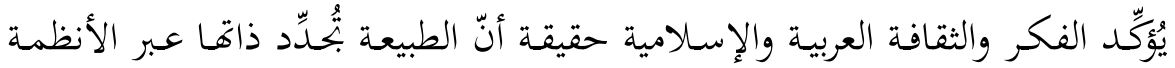

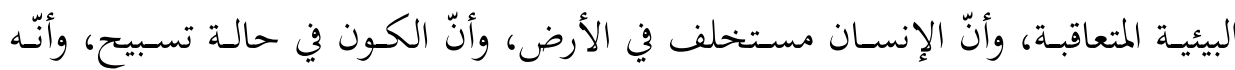

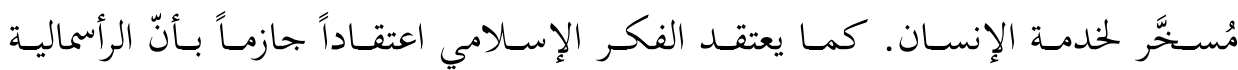

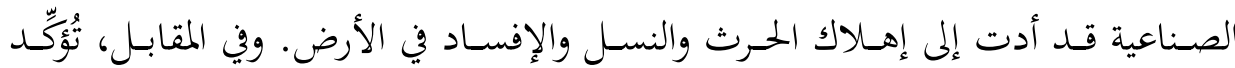


منظومة الثقافة الإسلامية مفاهيم: الإحسان، والزهد، والوحدة بين الأجزاء والكل. وفي

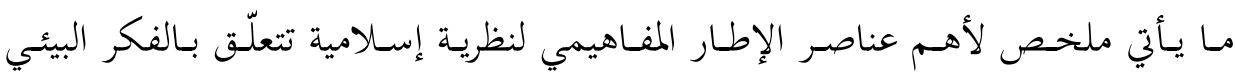

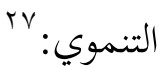

مهام الإنسان المستخلَف في الأرض، ومنها: منع الإسراف والظلم، وحماية موارد

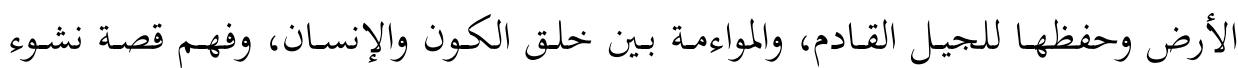

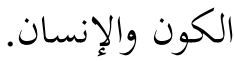

دور الإنسـان في عمـارة الكـون ضـمن السـنن الكونيـة والاجتماعيـة، وفي هـــا

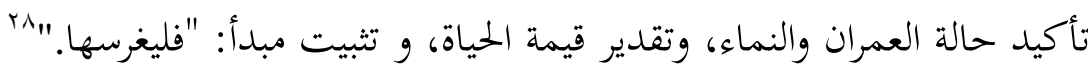

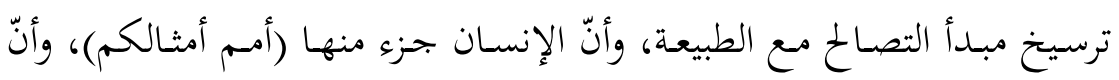
ذلك يُفضي إلى حالة مـن التنـاغم والتعايش والانسجام، وتقدير قيم الجمال في المحيط الخارجي بأنظمته البيئية والاجتماعية.

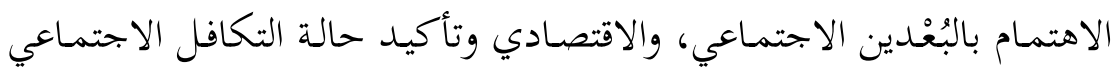

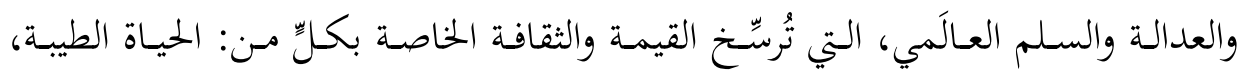
والكلمة الطيبة، والبلد الطيب، والأكل الطيب، والتنمية الطيبة. وعليه فنحن بحاجةٍ إلى مشروع يعيد بناء المعرفة بقالب جديد، ويدعم الفكر البيئي التنموي بمنأى عن الفكر الغربي، وصولاً إلى بناء منظومة معرفية ذات هوية تربط الأصالة بالمعاصرة. يُقدِّم الإسلام، بوصفه منهجاً للحياة، تصوراً متكاملاً لعلاقة الإنسان بالكون، التي

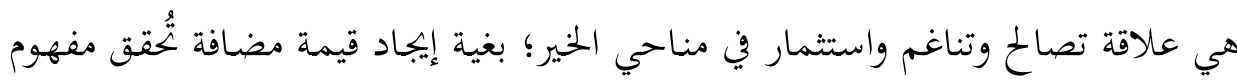

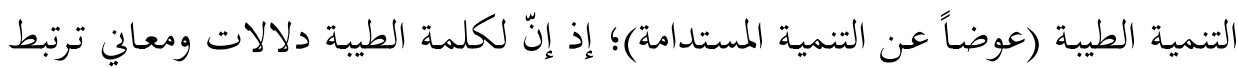

27 Al-Jayyousi, Odeh.(2012) Islam and Sustainable Development, Farnham, UK: Gower Publishing, July, 2012, U.K.

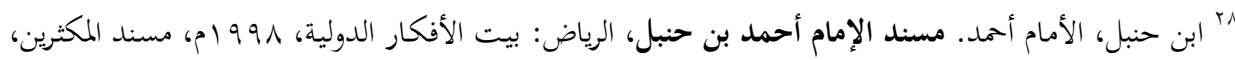

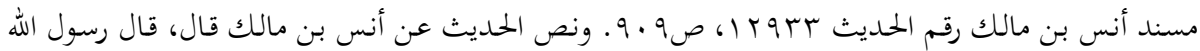

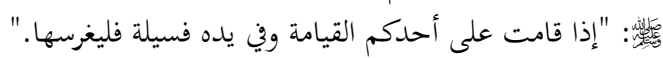


بالنوعية والحياة الكريمة. فعندما نتأمّل لفظه "طيبة" ومشتقاقا في الخطاب القرآين، بنحد

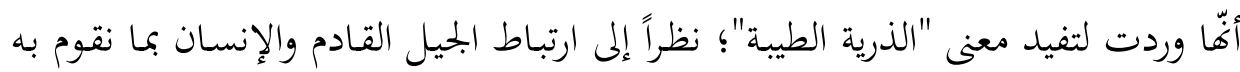

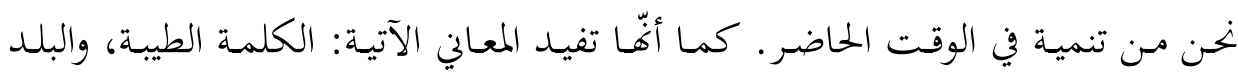

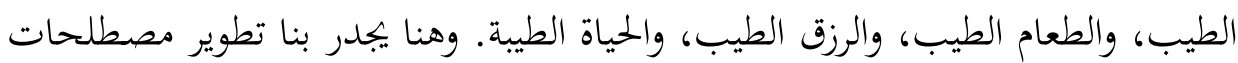

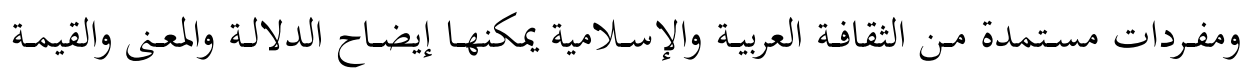

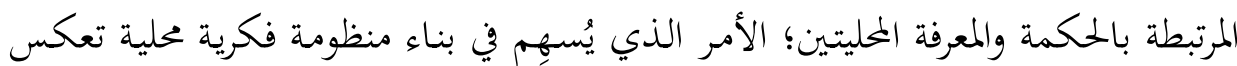

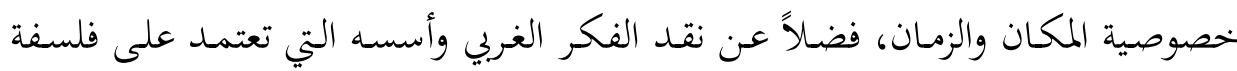

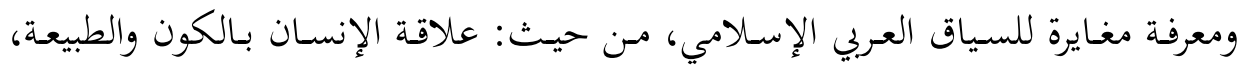

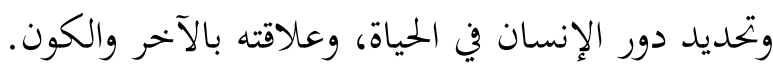

ولعلّ خير دليل على إشكالية نمط الحياة الغربي الذي يُكرّس ثقافة الاستهلاك؛ هو مـا ورد في كتـاب "الأمريكي المنهـك" (The Overworked American)، الذي الذي خلص إلى أن الفكر الرأسمالي يعتمد على مبدأ الاستهالك، وزيادة المنفعة أو تعظيمها.

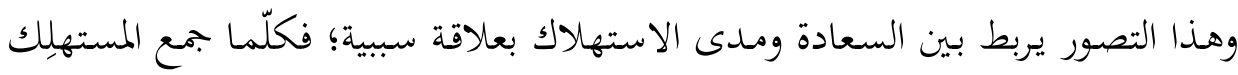

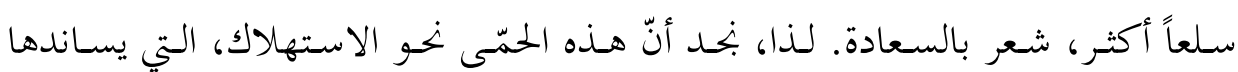
الإعلام والترويج، تهدف إلى تحويل الرغبات (Wants) إلى حاجات (needs). فالبيت

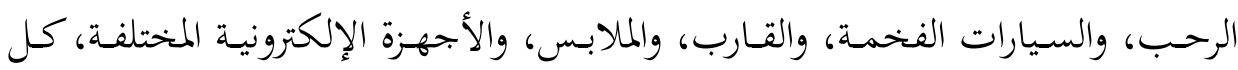

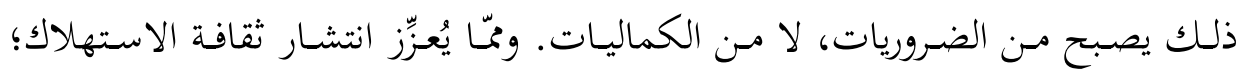

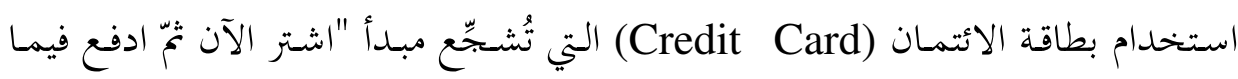

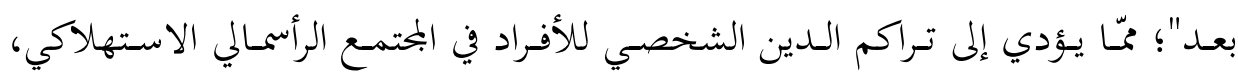
واستمرار الحلقة الشرسة في الربط بين الاستهالك والحصول على السعادة والراحة. وبذا،

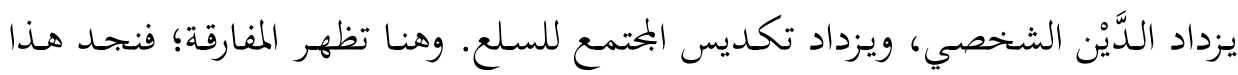

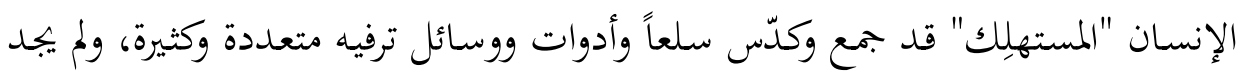

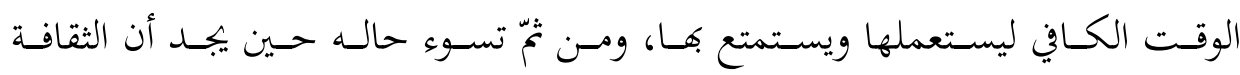

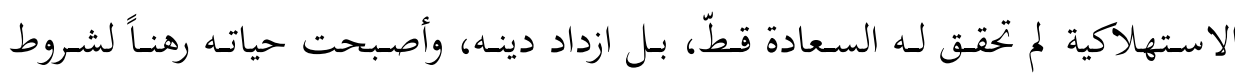




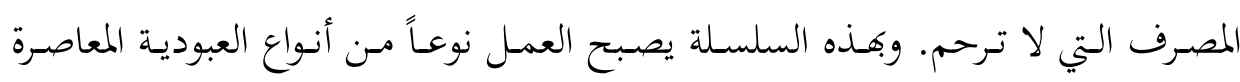
لتحقيق وهْم السعادة عبر الاستهلاك الذي ليس له فماية.

ومن المززن حقّاً أنّ مثل هذا النسق من الثقافة والثفكير أصبح سائداً في الدول

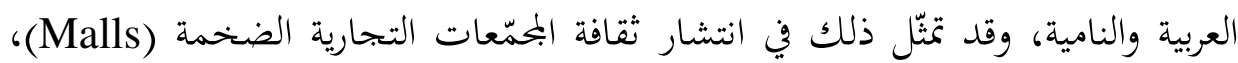

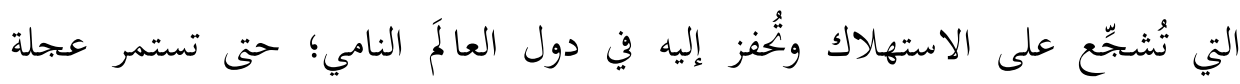

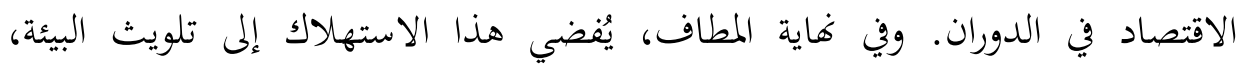

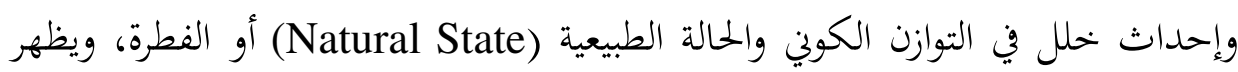

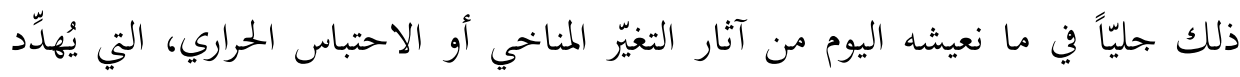

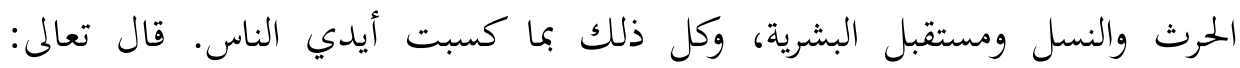

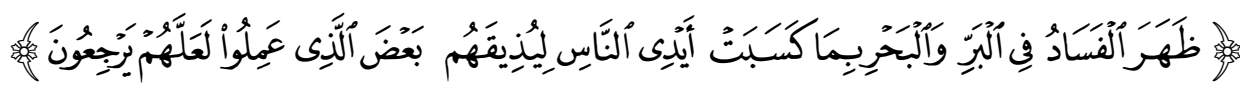

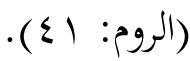

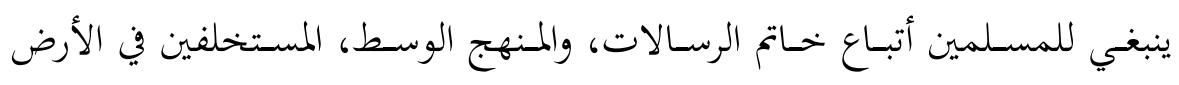

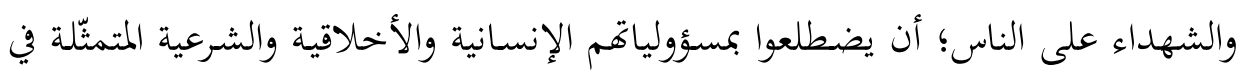

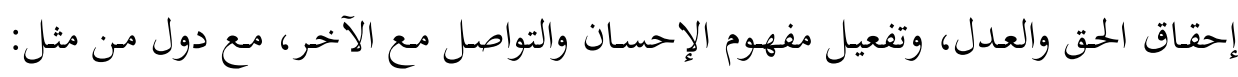

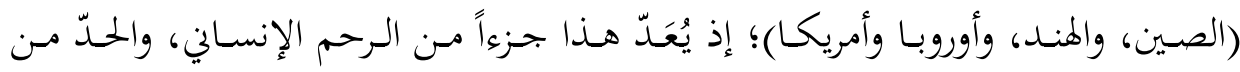

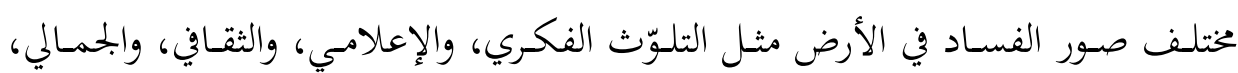

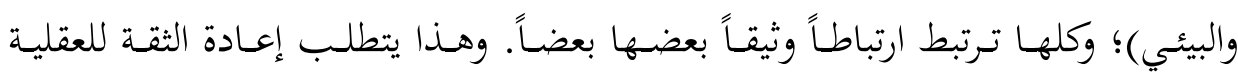

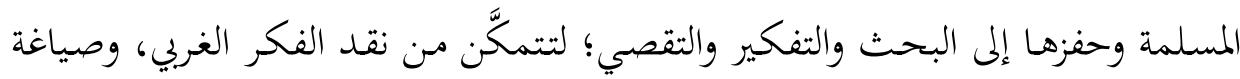

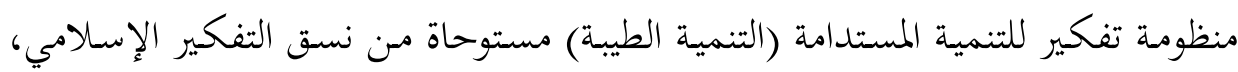
الذي يُؤِّد ثقافة الزهد، والتصالح مع الكون والآخر.

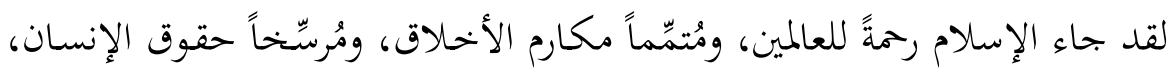

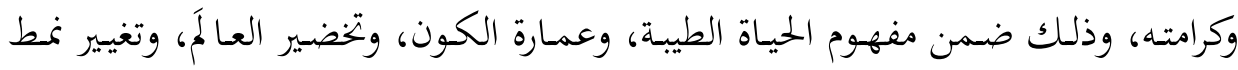

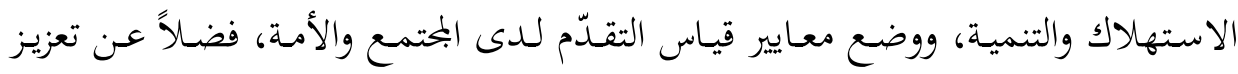
الإبداع، والتعلّم من الطبيعة (الذكاء المستمد من الطبيعة). 
ولعل أحد أهم الدروس التي يمكن أن نتعلّمها من أصحاب الحضارات القديمة، هو

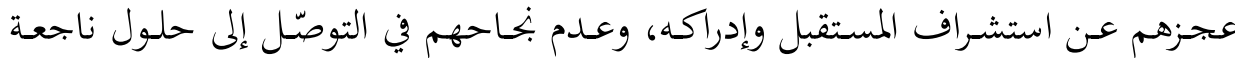

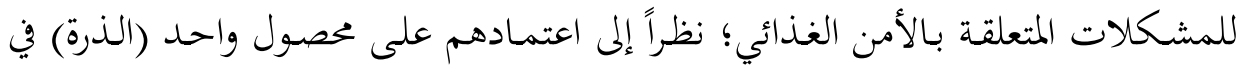

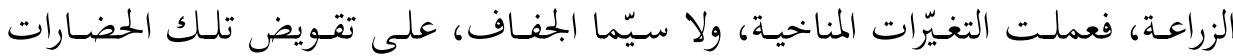

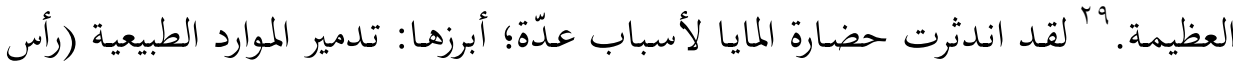

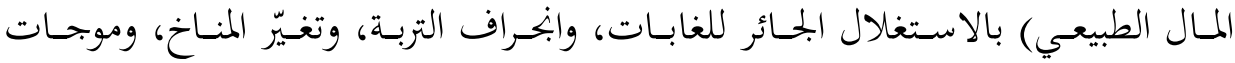
الجفــاف، بالإضـافة إلى النـزاعات والحــروب، والاهتمـام ببنـاء النصـب التذكاريـة، وعـدم

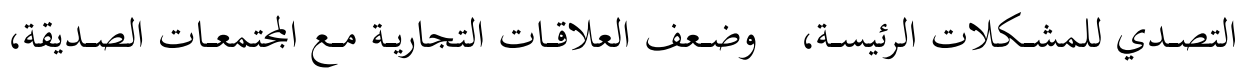

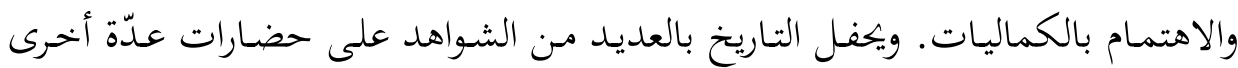

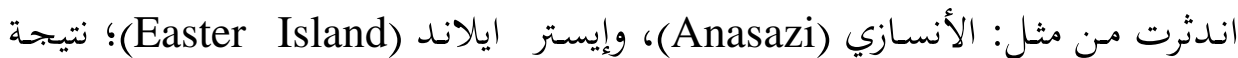
تفاقم الصراع بينها بعد استنزاف معظم الموارد البيئية المحيطة بها. إنّ إعادة بناء منظومة متكاملة لفكر الاستدامة من منظور اسلامي، يتطلّب صياغة نسق فكري جديد مستمد من الثقافة الإسلامية. وفي ما يأتي بيان لمكوّنات نموذج التنمية

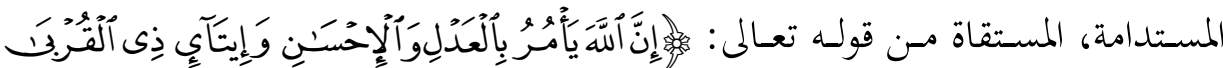

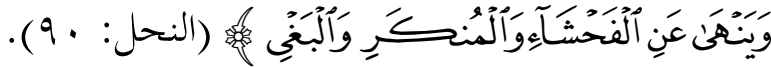

${ }^{29}$ Diamond, Jared. Collapse: How Societies Choose to Fail and Survive. London. London: Penguin Books, 2005, pp.136-156. 


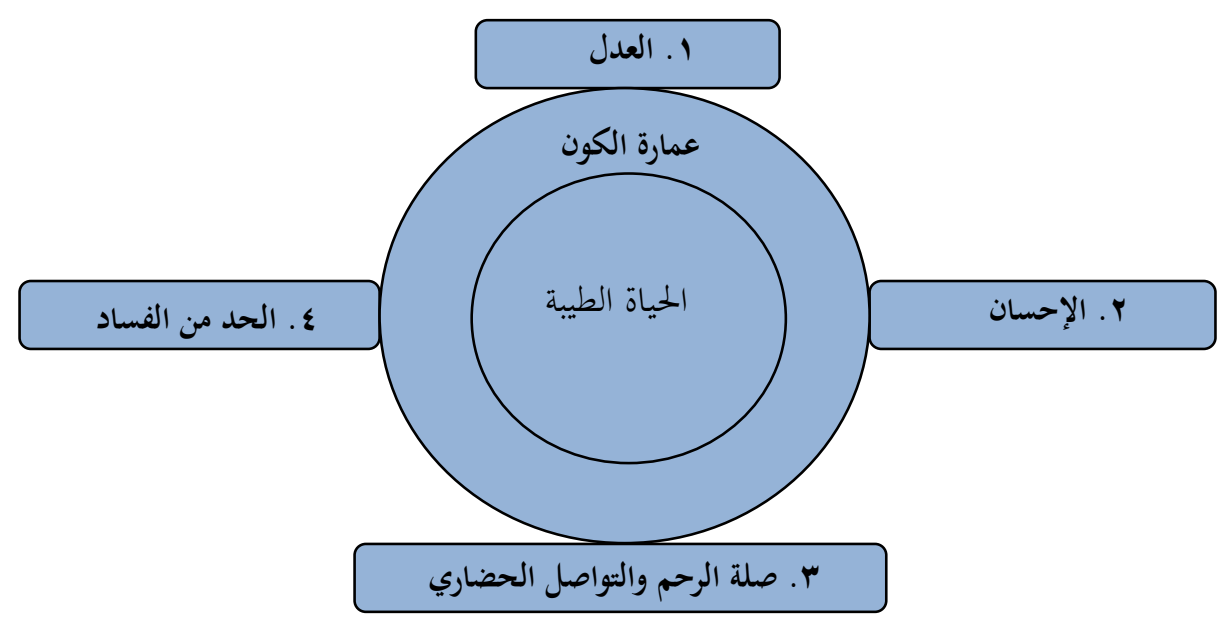

$$
\text { الشكل (1) (1) نموذج للتنمية المستدامة (الطيبة) من منظور إسلامي }
$$

يُوضِّح الشكل السابق مكوّنات النموذج الاسلامي للتنمية المستدامة، الذي تكون

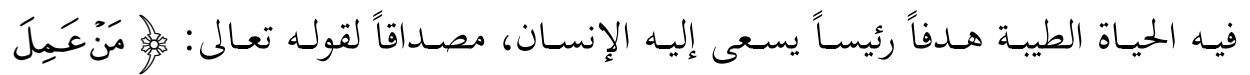

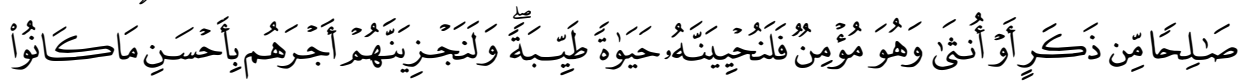

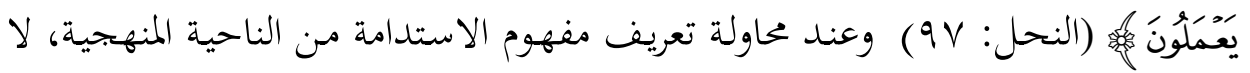

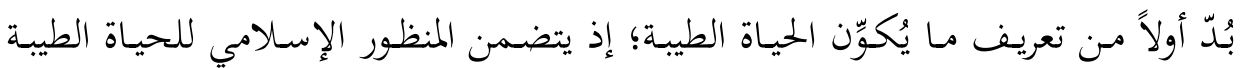

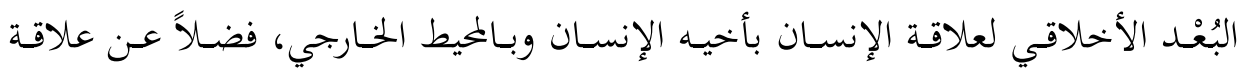

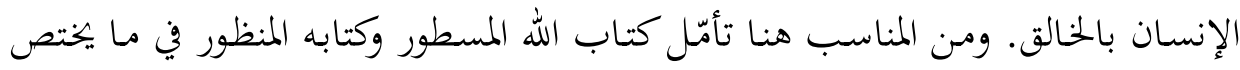

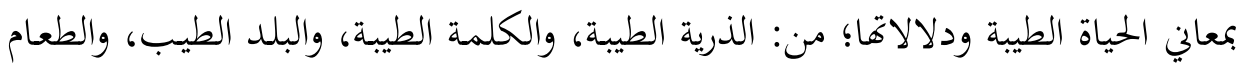
الطيب.

\section{الحياة الطيبة وعمارة الكون:}

في ظل إفلاس الحضـارة الغربية مـن البُعْد الروحي والأخلاقي والمالي، وتفشي الفقر

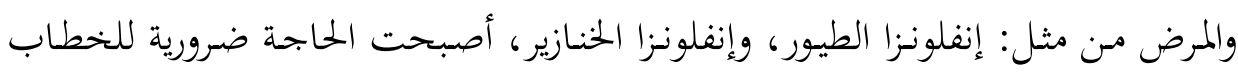


والتصـور الإسـلامي؛ بغيـة إصـلاح كلمِ مـن: البيئة، ورأس المـال الطبيعي، وحالة تقطيع

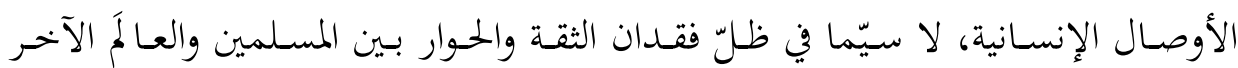

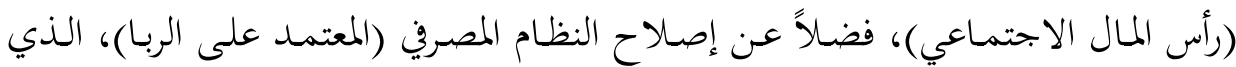

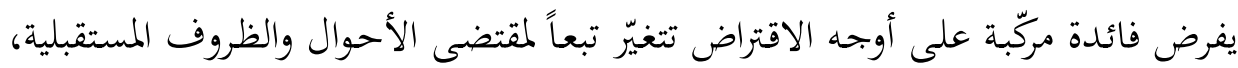

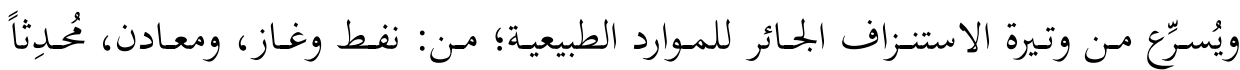

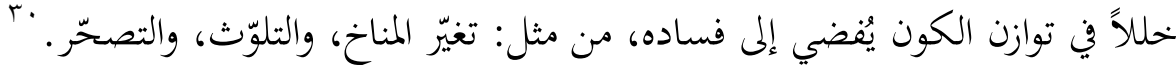

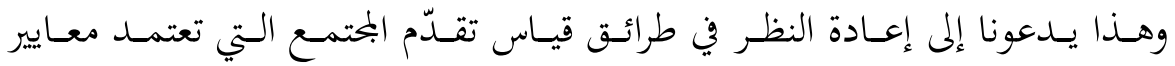
اقتصادية محددة وغير دقيقة، من مثل: الدخل القومي (GNP)، أو مؤشر التنمية البشرية

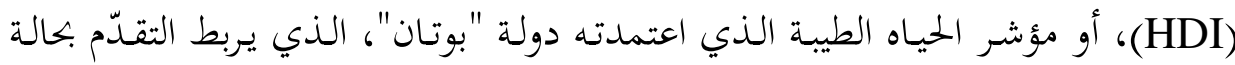

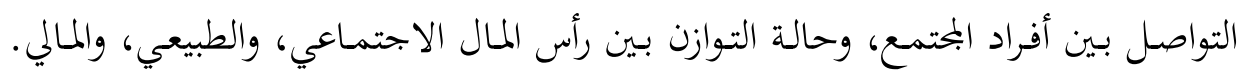

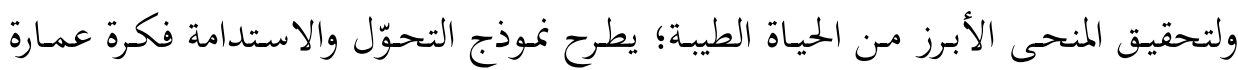

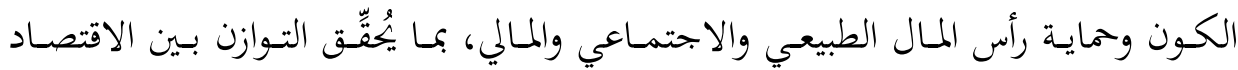

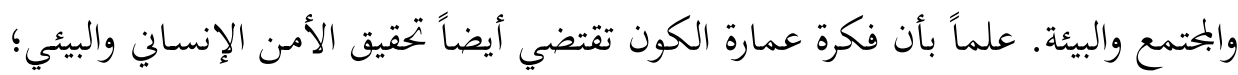

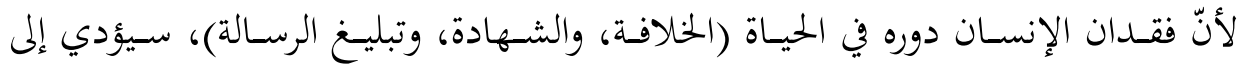

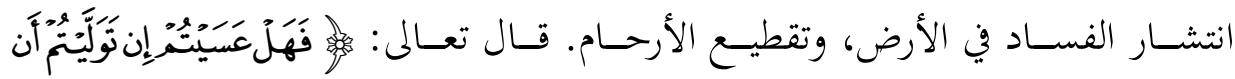

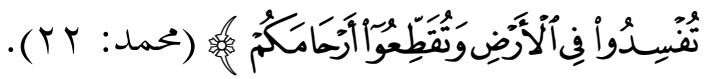
وفي ما يأتي بيان لعناصر النموذج المقترح للتنمية المستدامة من منظور إسلامي:

\section{1 ـ العدل:}

إنّ لفكرة العدل (Justice) والعدالة (Equity) عمقاً أساسيّاً في الفكر الإسلامي؛

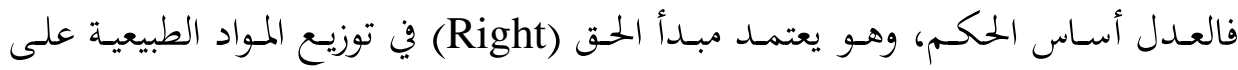

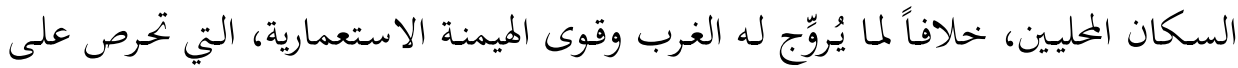
تغيير فكرة "الحق التاريخي" وحقوق الإنسان، وتحويلها إلى حق قائم على الواقع والحاجة.

${ }^{30}$ Chapra, U. Islam and Economic Development. New Delhi Publishers \& Distributors, 2008, p. 199-213. 
ومثال ذلك: الطرح الصهيوني لحقوق المياه في فلسطين، ومياه الأغمار العربية، والأراضي

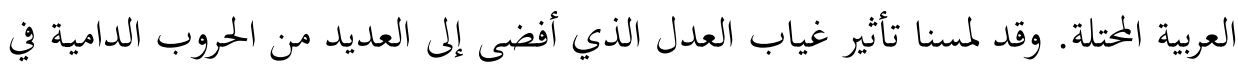

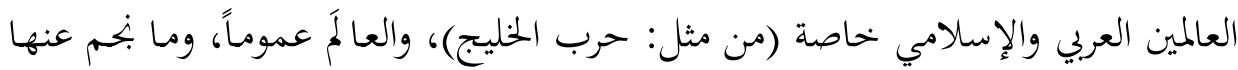

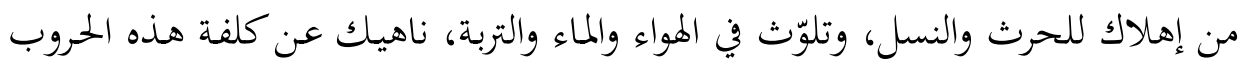

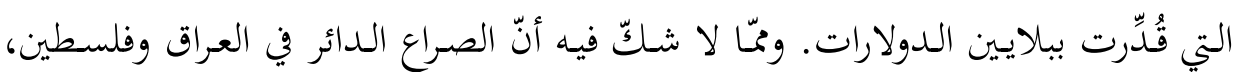

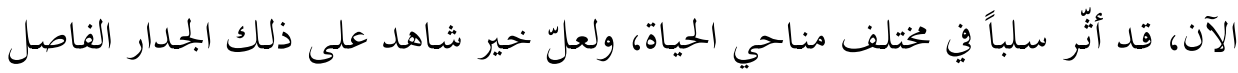

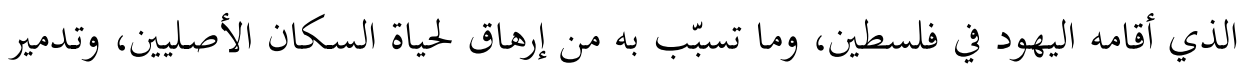

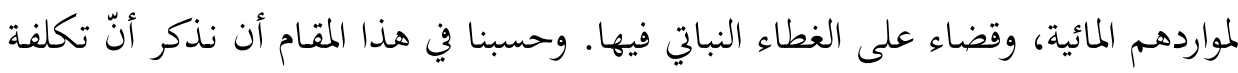

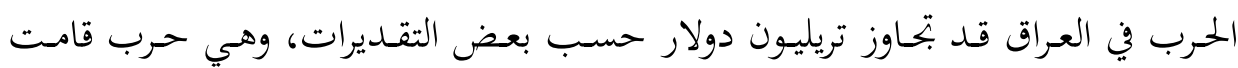

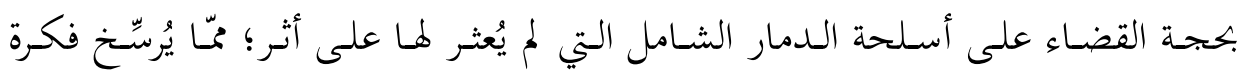
الاستعمار القائمة على البغي والسعي إلى التحكّم في مصادر الدول الطبيعية.

\section{Y.الإحسان:}

تتضـمن فكـرة الإحسـان دلالات متعـددة، مـن مثل: الجمــال الـداخلي، والتجويـد،

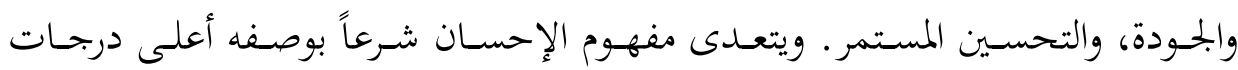

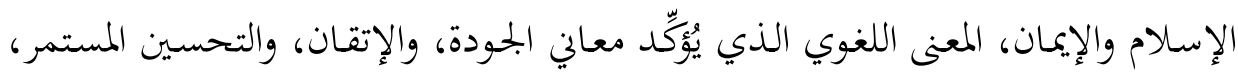

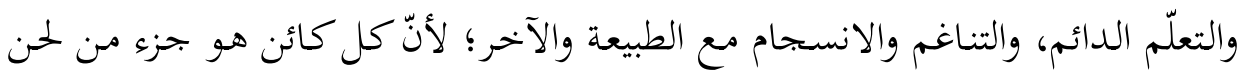

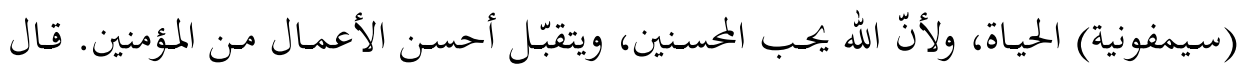

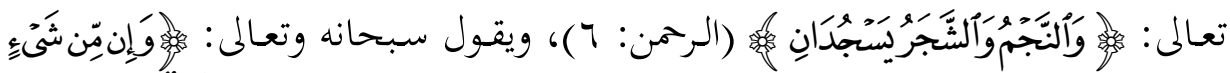

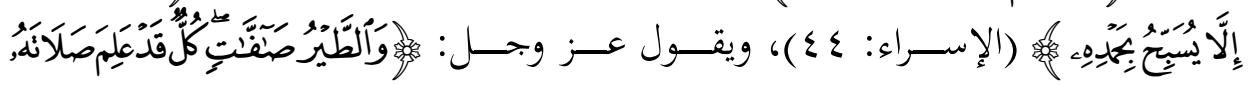

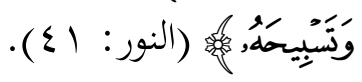

إنّ لفكرة الإحسان دلالاتحا وشواهدها في كتاب الله المسطور (القرآن) وكتابه المنظور

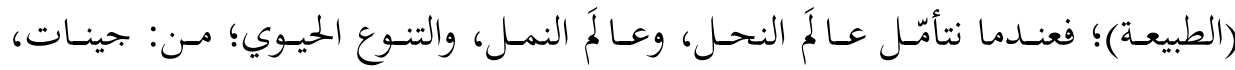

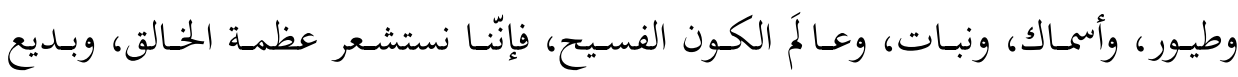

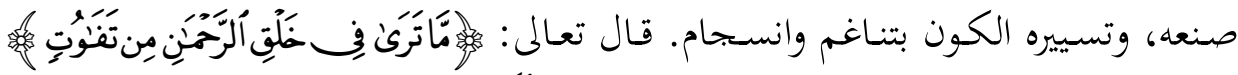

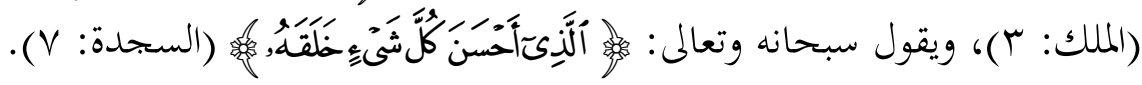


وبما أنّ الإسلام يحثث على طلب العلم والمعرفة؛ فإنّ المفهوم الرئيس لتوليد المعرفة،

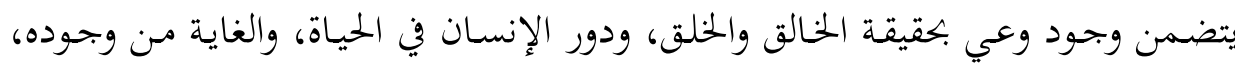

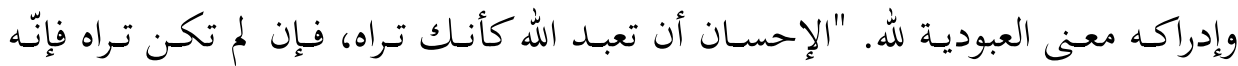

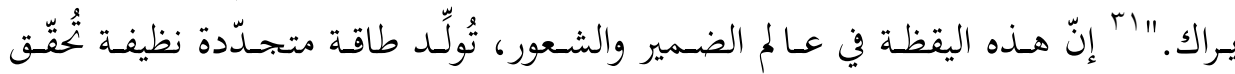

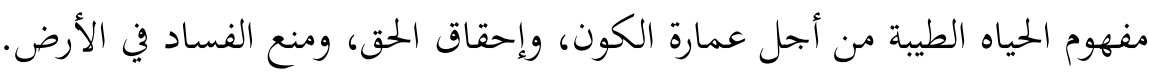
أمّا أسـاس الخير والإحسـان للأمة السمحة فيكمن في حياة عـا لم الضمير، وخشية

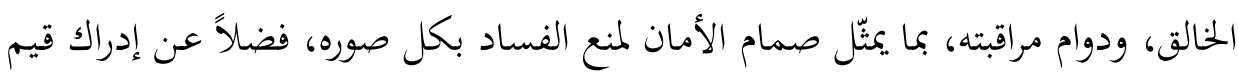

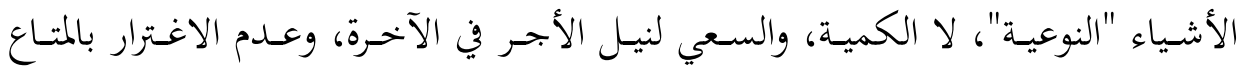

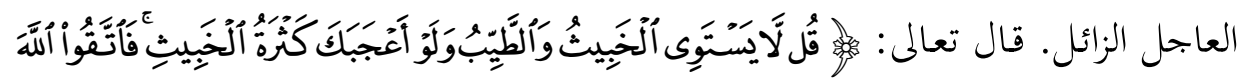

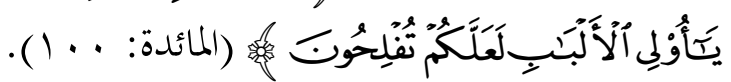

\section{r. (بلة الرحم والتواصل الحضاري:}

أشـار القـرآن الكريم إلى الحكمـة مـن خلق البشـر على اختـلاف ألسـتـهم وألكواهم

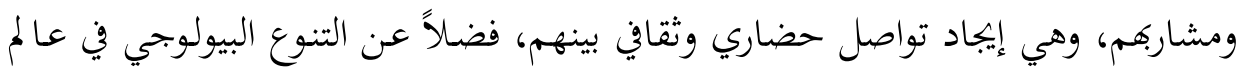

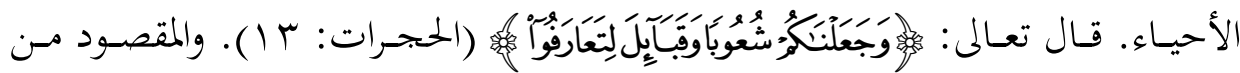

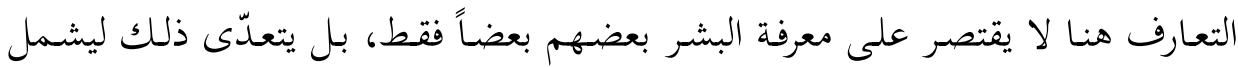

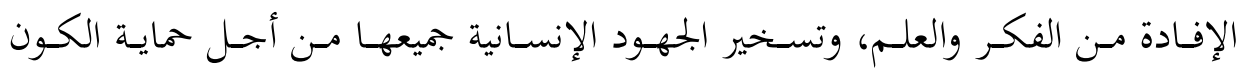
وإعماره.

فتحقِق معنى الخشية لله، والتدبر في عظمة خلقه عند علماء الطبيعة الذين يهتمون

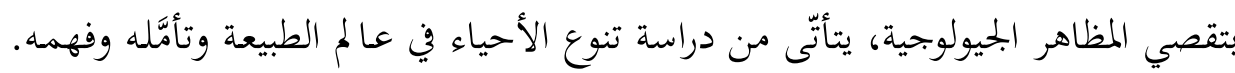

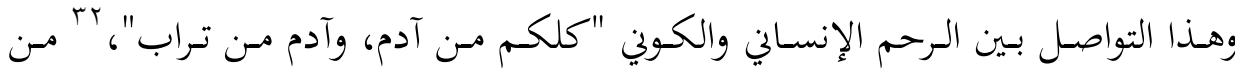

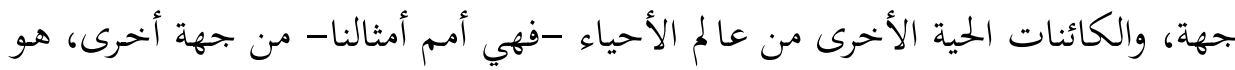
بام البخاري، محمد بن إسماعيل. صحيح البخـاري، دمشق: دار ابن كثير، كتاب: الإيمان، بـاب: سؤال جبريل

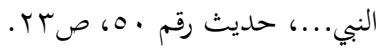

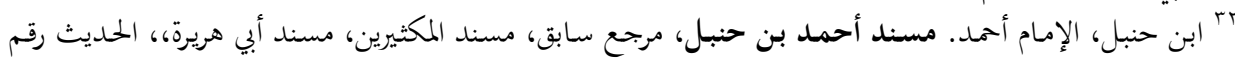

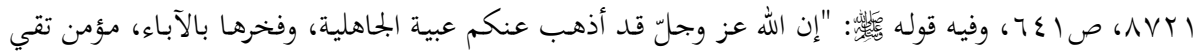

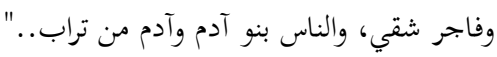


دعـوة راقيـة للتواصـل بـين البشـر والكائنـات مـن حولنـا. ونقيض ذلك يؤدي إلى فقـدان

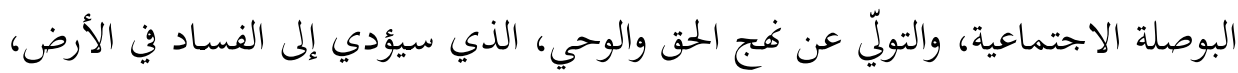

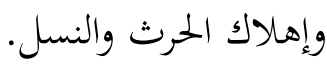

إنّ التحّول نحو الاستدامة وعمارة الكون من أجل تنمية الطبيعة يقتضي -ضمنيّاً -

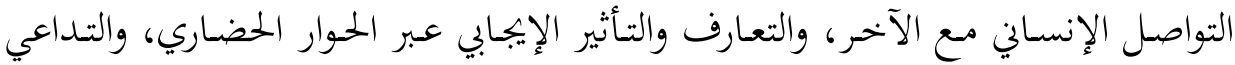

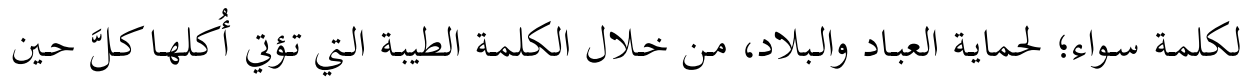

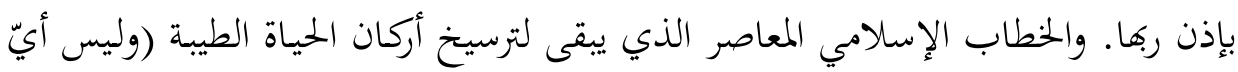

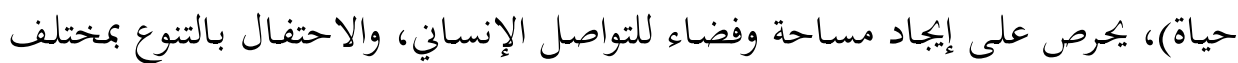
أشكاله.

إنّ بجاح العالمَ الإسلامي في تقديم نماذج حيّة عمليّة (مثل مكة الخضراء)، وتطوير

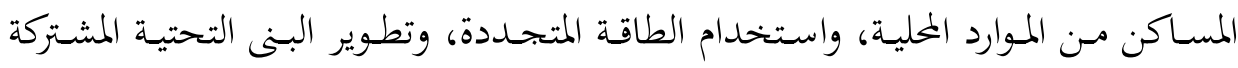

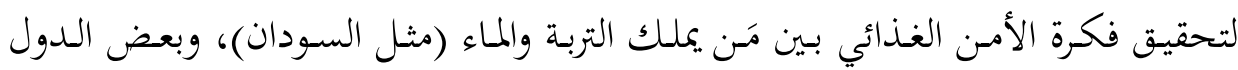

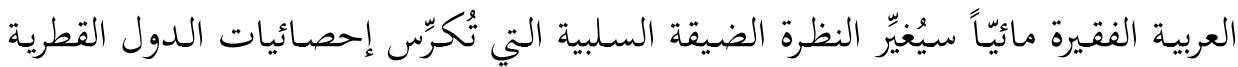

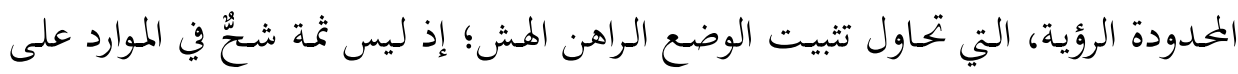

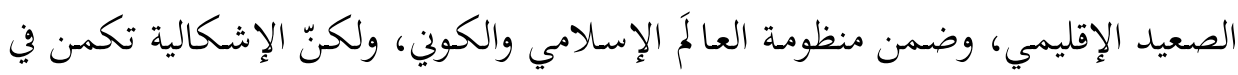

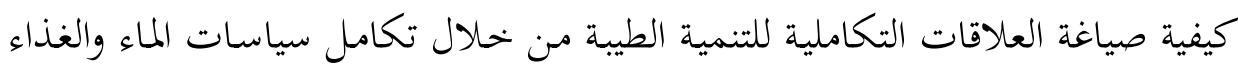
والطاقة والتجارة.

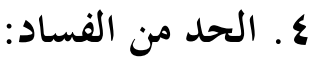

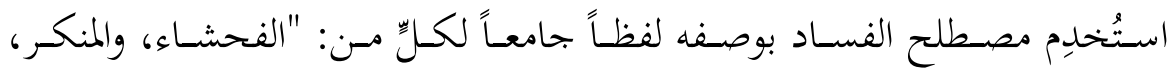

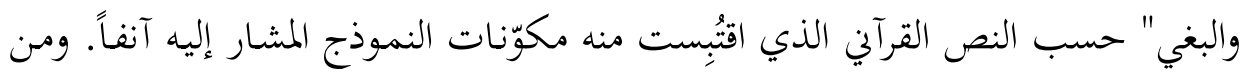

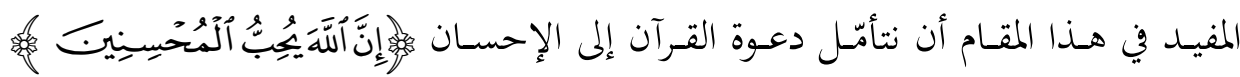

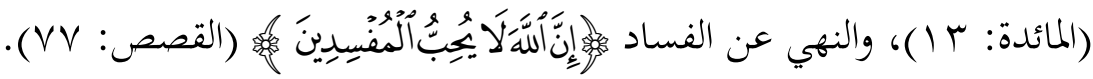

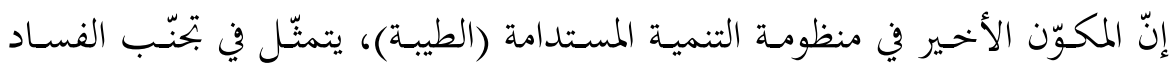
الذي يزخر به نموذج التنمية الغربي، بما في ذلك: اعتداء الدول الصناعية والشركات العابرة 
القارات على موارد العالمَ الثاني، وسلب السكان الأصليين حقوقهم بذريعة الأمن المائي

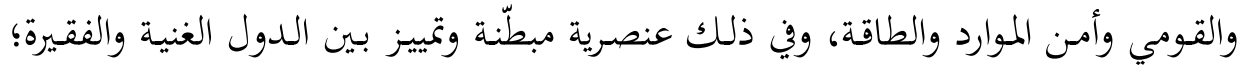
فالحروب والنزاعات في كلٍٍ من: العراق، والسودان، وفلسطين، هي خير شاهد على مدى

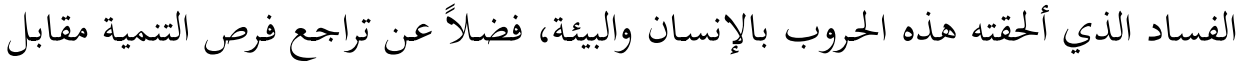

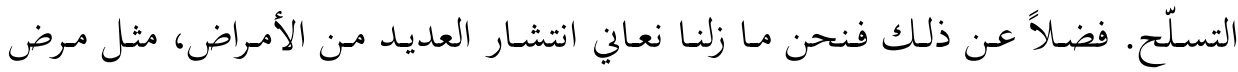
الإيدز الذي يزهق أرواح ملايين البشر في إفريقيا سنويّاً، ناهيك عن الفقر المدقع، وتغيّر

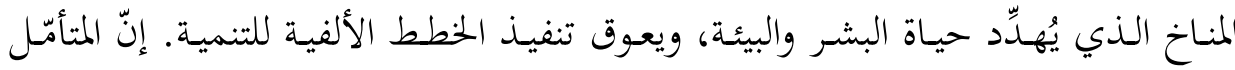

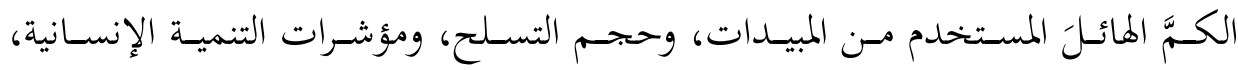

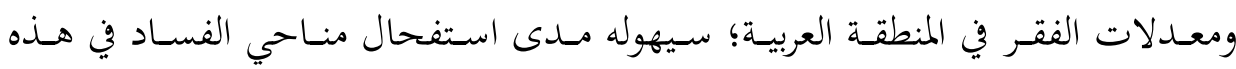
المنطقة.

ولعـلّ مـن المهـم معالجـة إشـكالية المفارقـة بـين النظريـة الفكريـة الإسـلامية، بوصفها

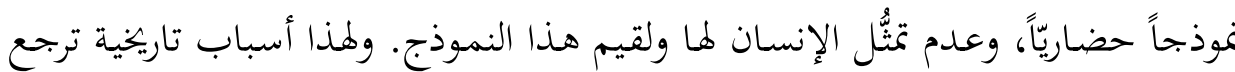

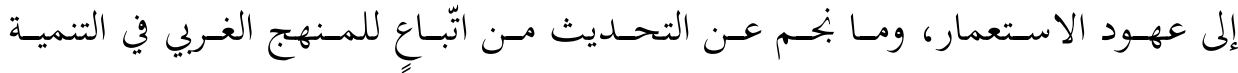
والاستهلاك والتعليم، والعلاقة مع الطبيعة والآخر؛ الأمر الذي أفضى إلى تفكيك الكن بنية

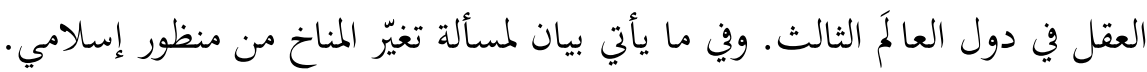

رابعاً: التغيّر المناخي من منظور إسلامي: كشفت لنـا التقنيات الحديثة، وعلوم المناخ وجود دورات متأرجحة مركّبة للمناخ.

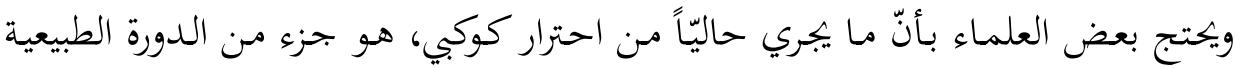

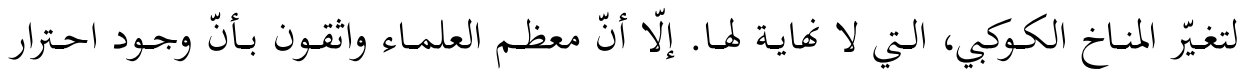

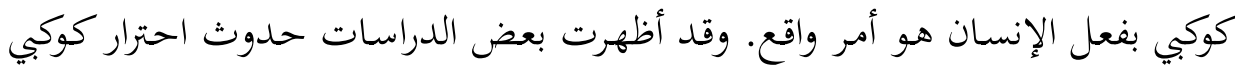

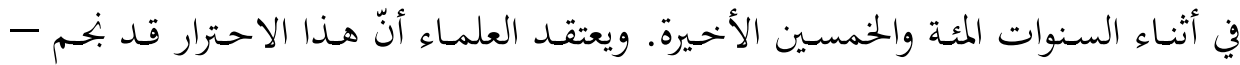

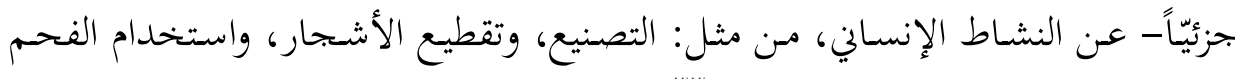
والبترول، وغيرهما من الوقود الأحفوري.

${ }^{33}$ Hussain, Muzaamal. Op cit. p. 6-8. 


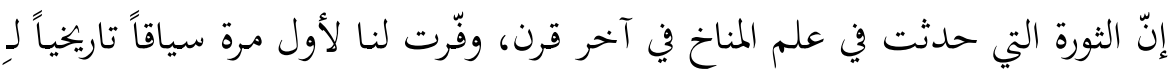

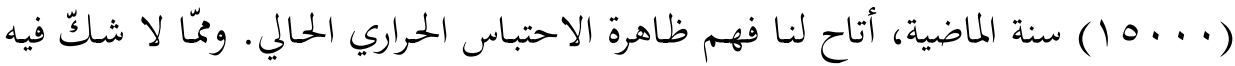

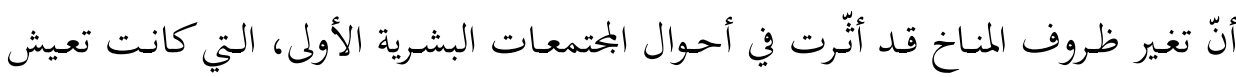

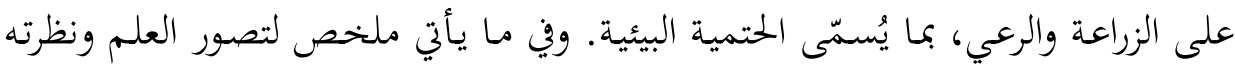

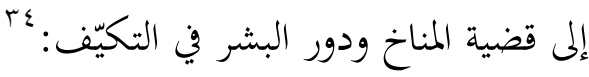

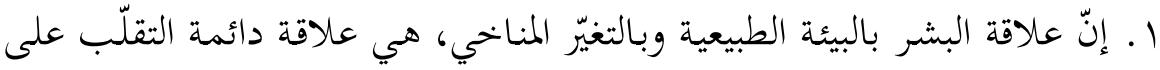

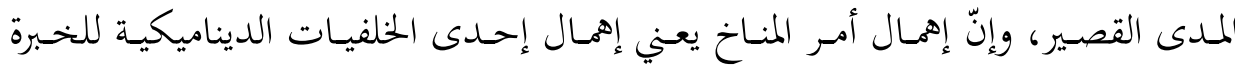

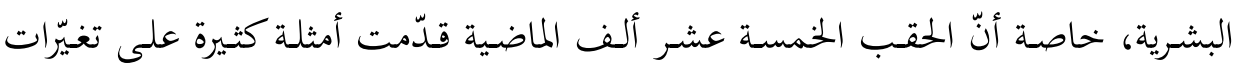

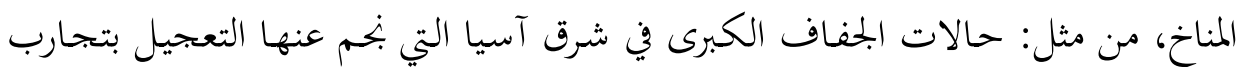

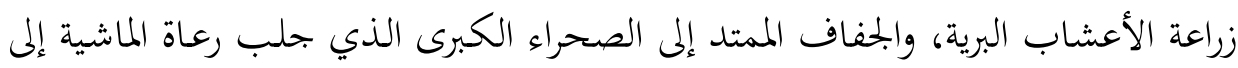

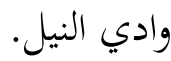

r. إنّ البشرية غدت أكثر استهدافاً لأخطار تغيّرات المناخ على المَديْين: القصير،

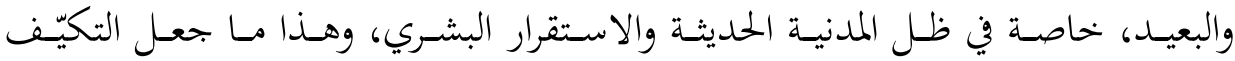

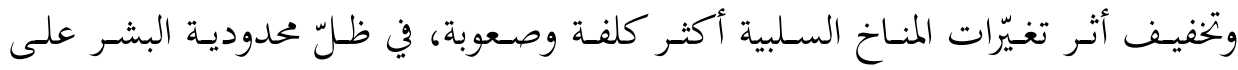

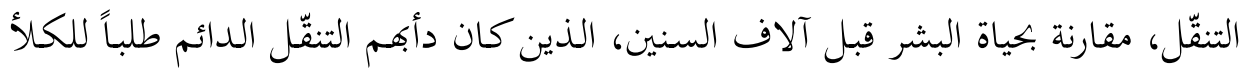

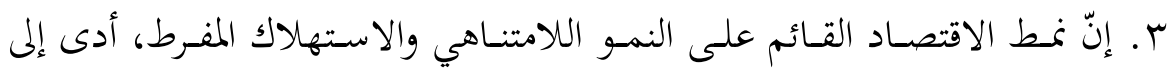

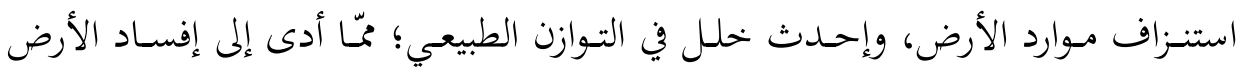

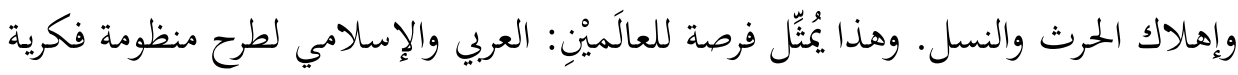

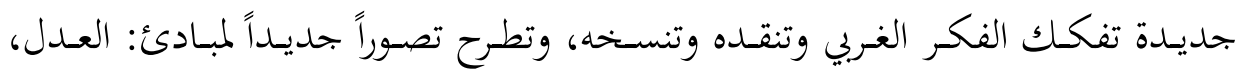

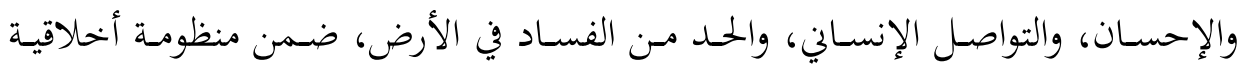

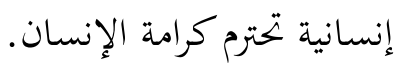

${ }^{34}$ Fagan, Brian (2005). The Long Summer: How Climate Changed Civilization. New York: Basic Book Publishing, 2005, p. 12-18 
ع. الاستفادة مـن بتحارب أصحاب الحضـارات المائية الأولى (مثل حضـارة مـا بـين النهرين) قبل خمسة آلاف عام، فقد واجه قاطنو هذه المنطقة تقلبات المناخ وتأثيرها في

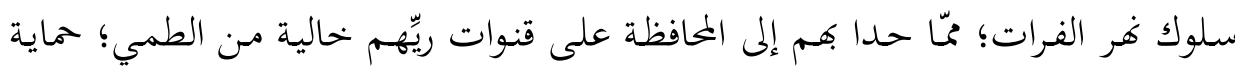

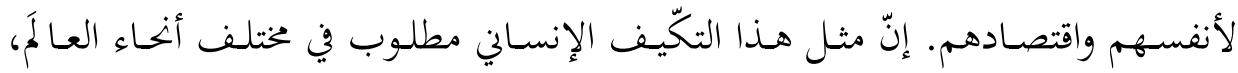
وعلى الناس تناسي مصالحهم الآنية والأنانية الضيقة والسلبية، ويتكاتفوا معاً؛ بغية حماية كوكب الأرض من الخطر المحدق. وفي حال لمُ يُسبّب الضغط المناخي اهياراً كاملاً، فإنه كثيراً مـا يُعنّز على إعـادة التنظيم الاجتمـاعي والسياسي، فضـالًا عن تشجيع الابتكار التقني والتحوّل المؤسسي البحتمعي.

ه. دراسة تذبذب درجات الحرارة وآثاره السلبية في الحياة والكون؛ فقد شهد صيف

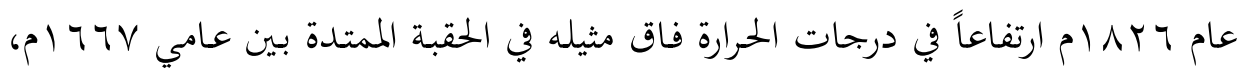

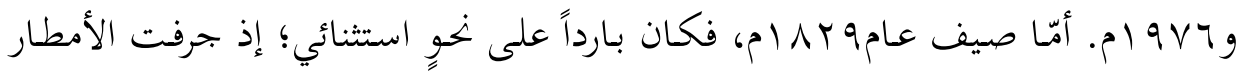

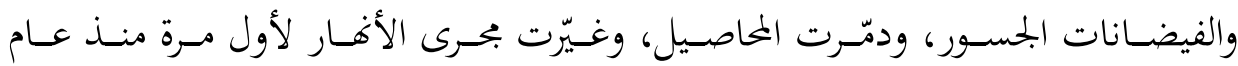

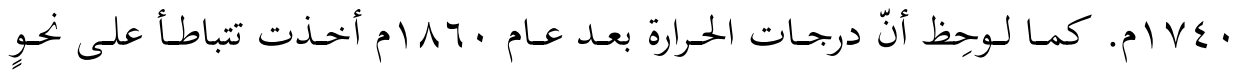
متواصل حتى يومنا هذا؛ مُّا يؤكّد أنّ هذا التقلّب في درجات الحرارة ناجم عن استخدام الوقود الأحفوري وغيره من الملوّثات، وأنّه ليس جزءاً من التذبذبات الطبيعية لتغيّر المناخ. 7. إنّ حماية الغطاء النباتي والحـراج والمحميات الطبيعية والمائية، تُسهِِم في الحـد مـن

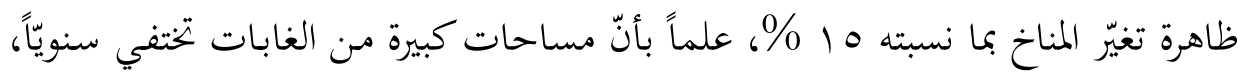
وهي تُماثِل مساحة ولاية أريزونا الأمريكية، أو جمهورية مصر تقريباً. كما أنّ ذوبان الجليد في القطب الشمالي على نحوِ غير مسبوق يُندِز بآثار سلبية قد تطال العالَّ أجمع. V. على الرغم من قدرة البشر المذهلة على التكيّف مع الأحوال البيئية المختلفة، إلّا

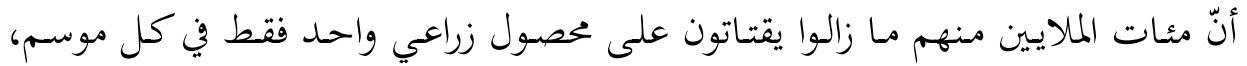

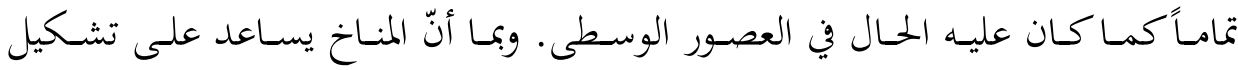

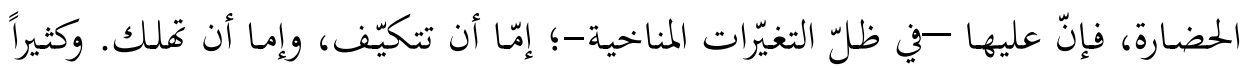


ما كانت هذه التغيّرات المناخية مفاجئة للنخبة الحاكمة، التي كانت تُنكِر الخطر المحدق هما، أو تتجاهله؛ الأمر الذي أدى إلى فناء حضارات عديدة.

وفي ظلّ تحديد نسب الانبعاثات الغازية، والتزامات الدول الصناعية المالية نحو الدول

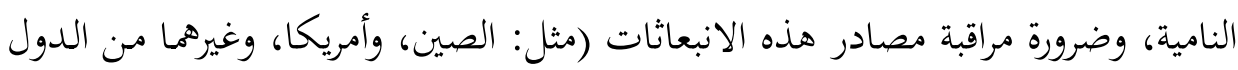

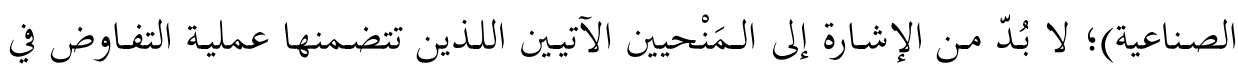

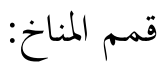

الأول: إنّ عملية التفاوض السياسي بين الدول الصناعية (الثمانية الكبار)، والدول

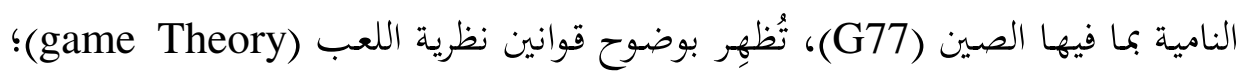

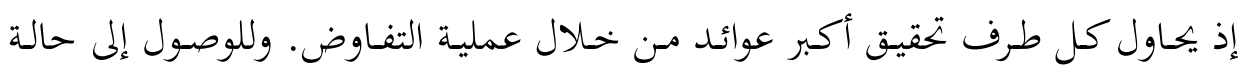

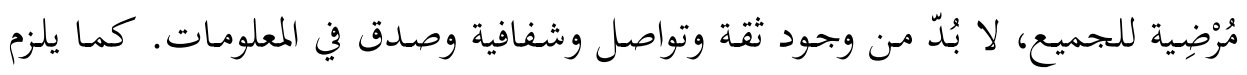

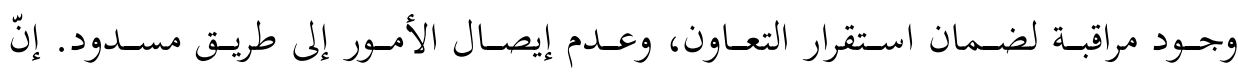

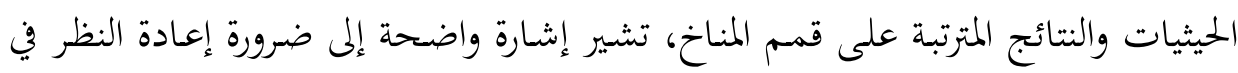
منهجية إدارة الحياة على هذا الكوكب وطرائق تسييرها.

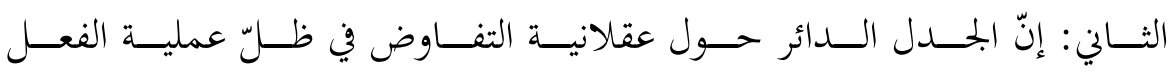
الجمعي(collective action)، التي تتضمن خيارات اجتماعية (social choices)

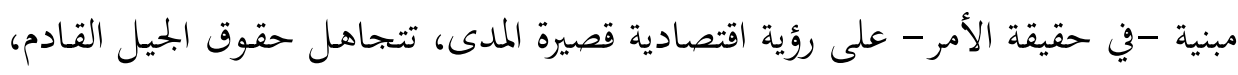

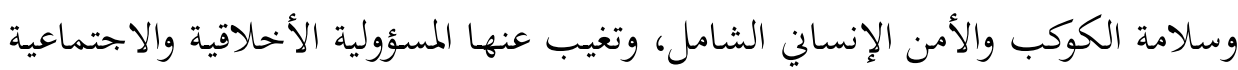

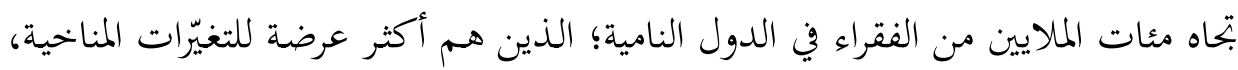

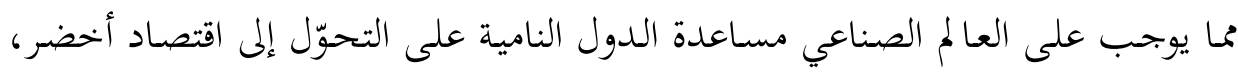

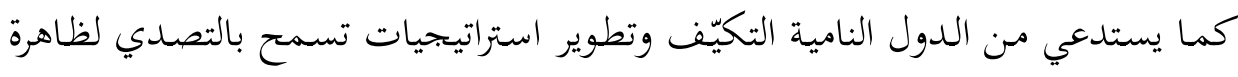
تغيّر المناخ عبر زيادة كفاءة الطاقة، وحماية الغطاء النباتي والمحميات. يمكن للعالَميْن: العربي والإسـامي الإفادة من نتـائج اجتماعـات القمـم العالميـة في

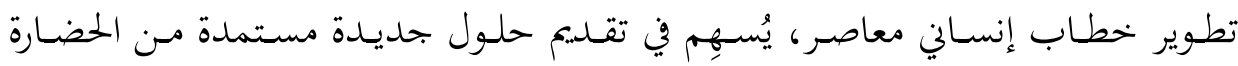

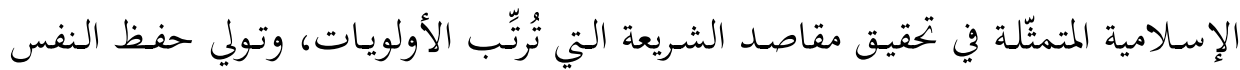


والنسل أهمية أكثر من حفظ المال، وتسعى لتعزيز معاني البر والعدل والإحسان، والحمد من الفساد، والتواصل بين الأرحام.

ومن هذه الحلول والمبادرات على سبيل المثال:

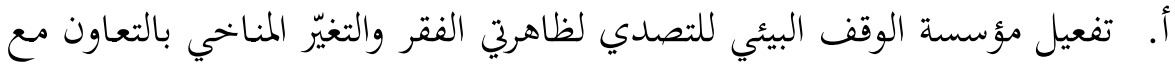

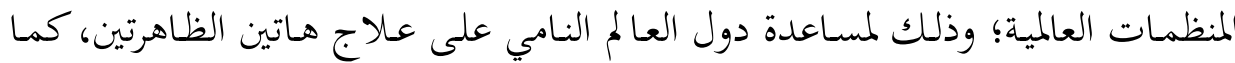

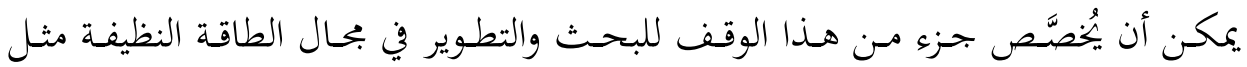

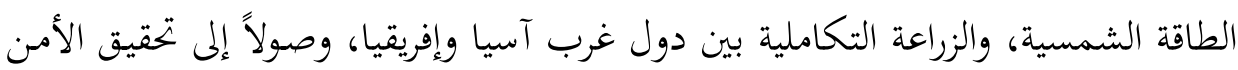
الغذائي والمائي في ظلّ العولمة.

ب. تطوير نماذج لاقتصاد دائم الخضرة، من مثل: المدن، والقرى الخضراء. ولعلّ أبرز

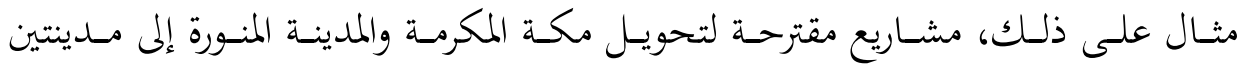

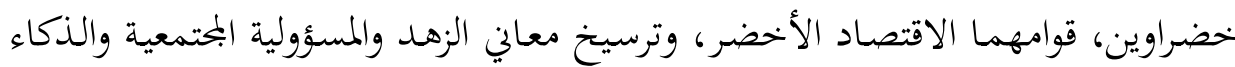
المستمد من الطبيعة.

ت. تطوير شبكة من الجامعات العربية والإسلامية والجامعات العالمية لدراسة أحوال

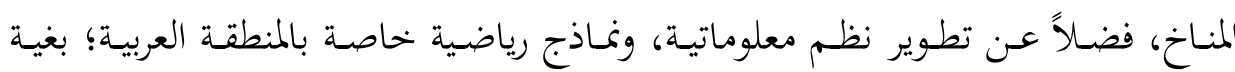

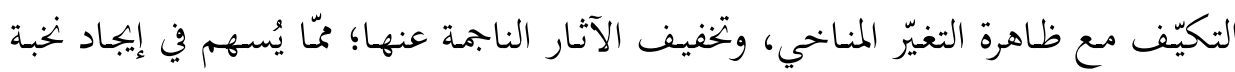

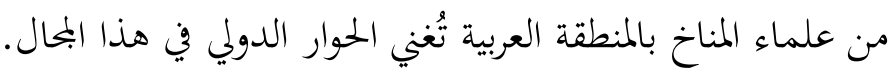

خاتمة:

تبيّن لنا مـن خلال الدراسة بأن ثمة حاجة ماسّة لتلمّس أطر عامة للنظر في التنمية المستدامة (الطيبة) من منظور إسلامي عن طريق المحاور الآتية:

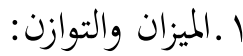

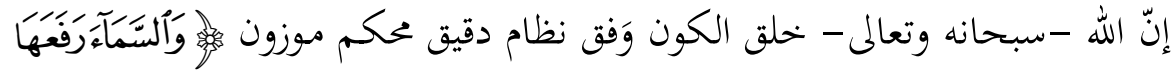

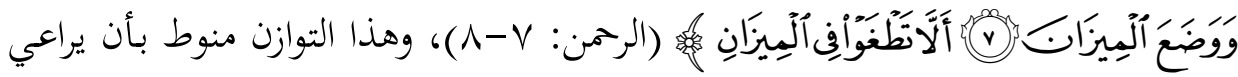

35 Chapra, U. Islam and the Economic Challenge. Herndon, VA: International Institute of Islamic Thought, 1992, page 201. 
الإنسـان السـن الكونيـة؛ لكيلا يُحـدِث فسـاداً في الأرض؛ لأنّ الفسـاد هـو نقيض لحالة

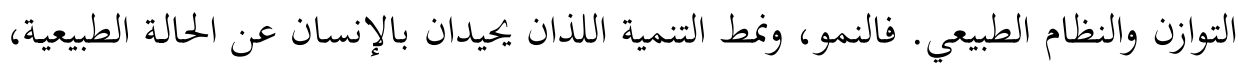

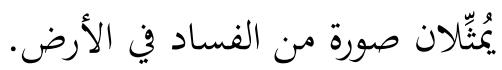
r. الزهد والاقتصاد في العيش: يحـرص الإسـلام على تأكيــ مبــأ الاقتصـاد في العـيش، وعــدم الإسـراف، وعـدم

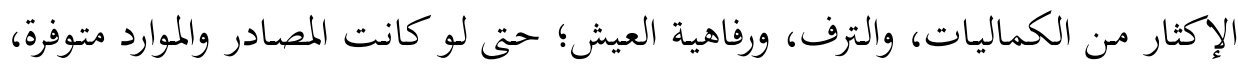

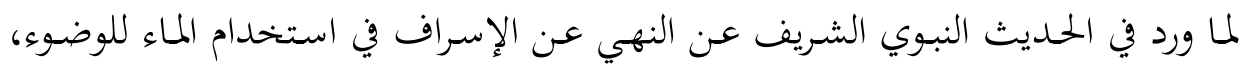

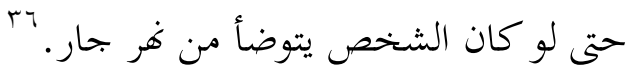
إنّ هذا الاقتصاد في العيش يعني الحدد من الاستهلاك المفرط، ومن تئّ تقليل استهاكك

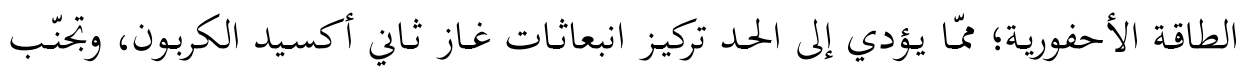

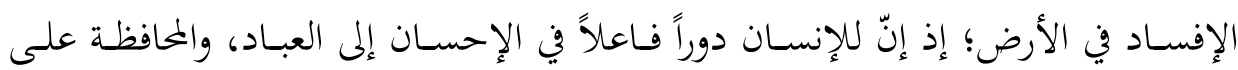
الكون.

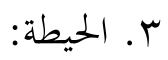
إنّ ضوابط الشريعة الإسلامية تُؤِّد القاعدة الفقهية: "درء المفاسد مُقدِّم على جلب المصالح". لذا، يجب مراعاة مبدأ الحيطة (Precautionary Principle)، الذي يقضي لوني

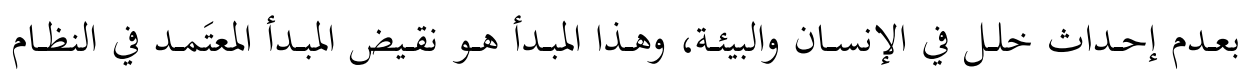

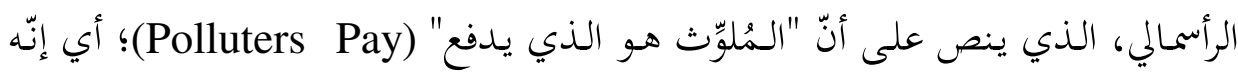

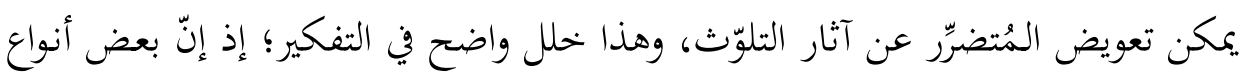

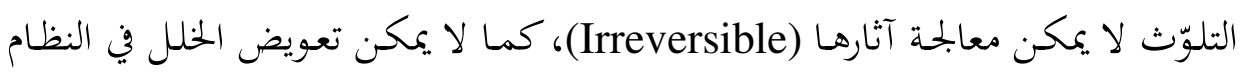
الطبيعي بالمال. وهنا يتجلّى تأكيد الإسلام وحرصه على البوصلة الاجتماعية بأن تكون وَفق الشرع؛ حتى نحافظ على موارد الأرض، وعلى سوية التواصل الإنساني.

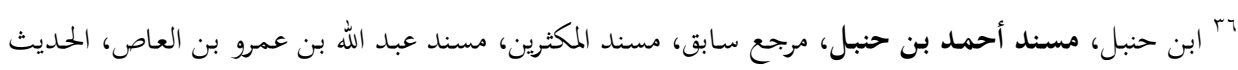

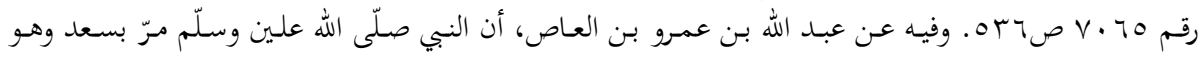

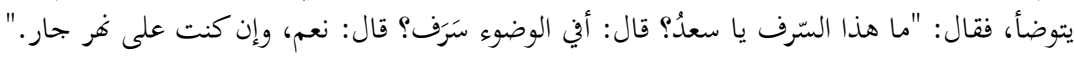




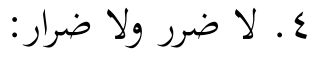

يسعى الجحل الدائر في قضية التغّير المناخي، بوصفه عملية تفاوض سياسية عبر ما

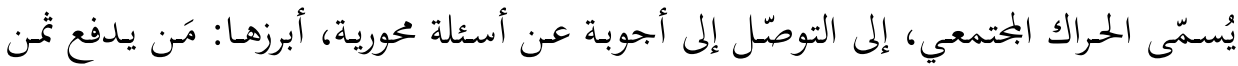

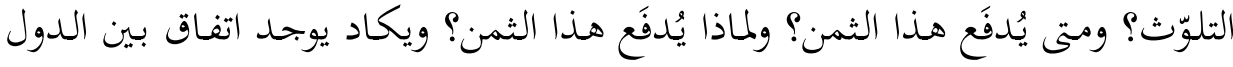

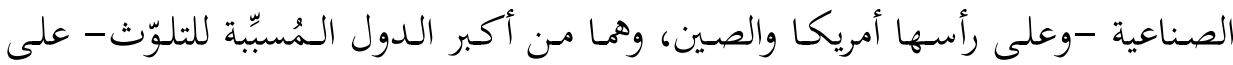

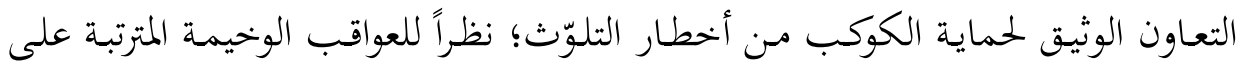

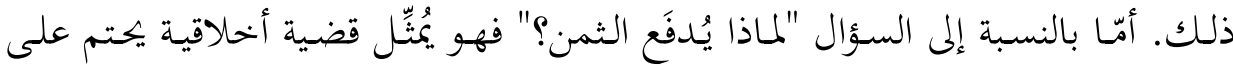
العالمَ الصناعي المُلوِّث الاضطلاع بمسؤوليته في معالجة آثار التلوّثث. وعليه، فإِّ القاعدة

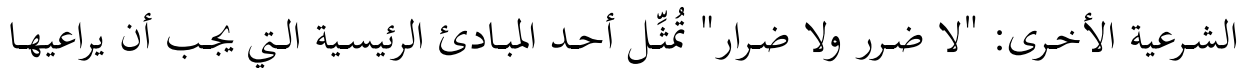

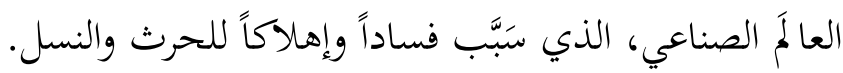
هـ مستقبل الأجيال القادمة:

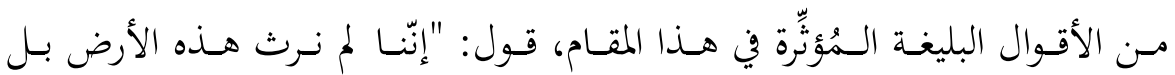

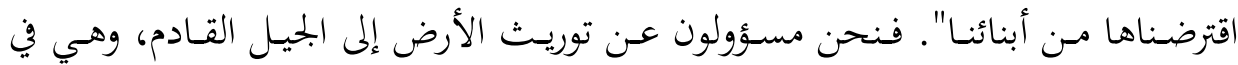

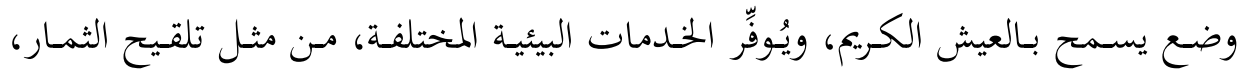

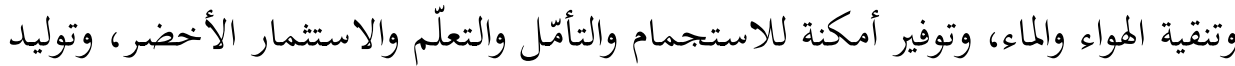

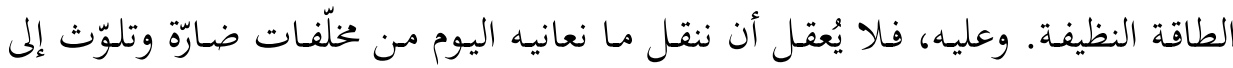

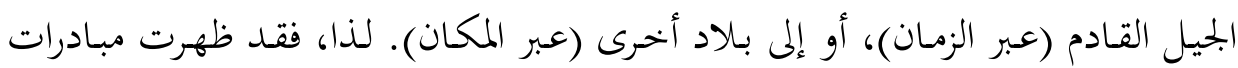

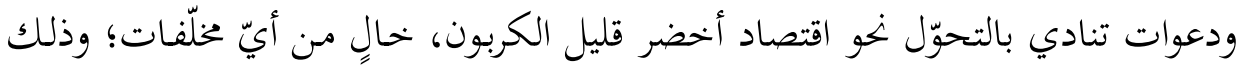
عبر الإنتاج النظيف، وزيادة كفاءة الطاقة، والاستثمار في الطاقة المتجددة، وحماية الموارد

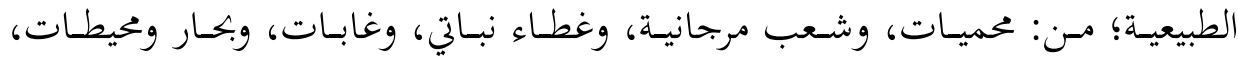

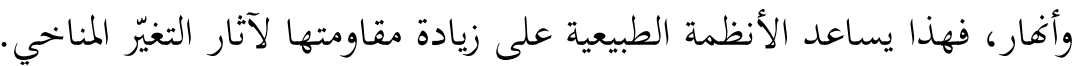

$$
7 \text { ـ النظام المصري والربا: }
$$

إن المبدأ الذي يقوم عليه الاقتصاد الرأسمالي هو مبدأ الفائدة المركّبة؛ التي يعتمدها في

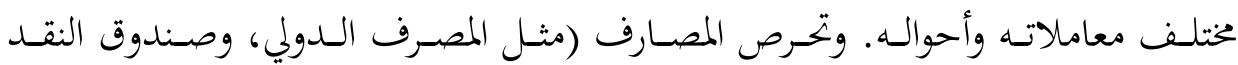


الدولي) على إقراض الدول والأفراد؛ بغية ضمان استمرار أنشطة القطاع المصرفي الذي

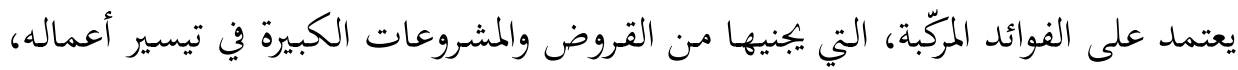

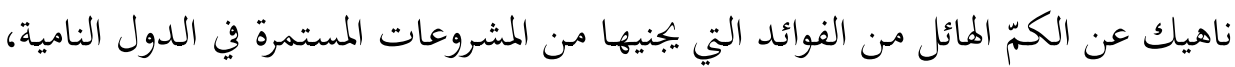
التي تستنزف الموارد الطبيعية والطاقة الأحفورية فيها. إنّ استنزاف سلع المستقبل وحست وحسابها

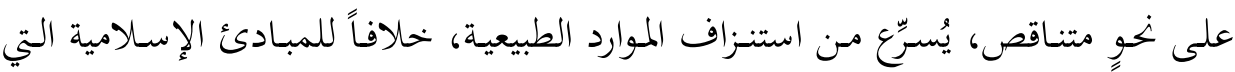

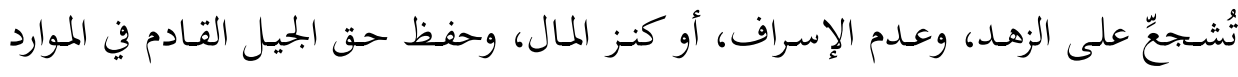

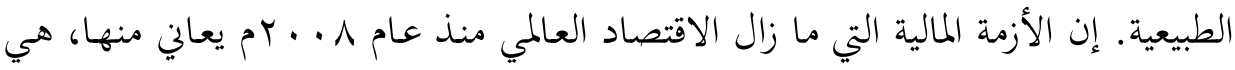

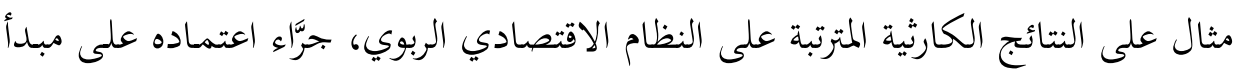

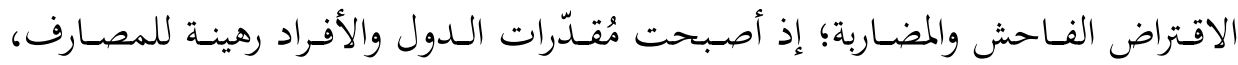

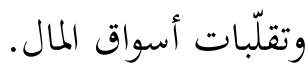

وبناء عليه نحن بأمس الحاجة إلى تطوير فكر جديد يستوعب ماهية الكوكب الأزرق

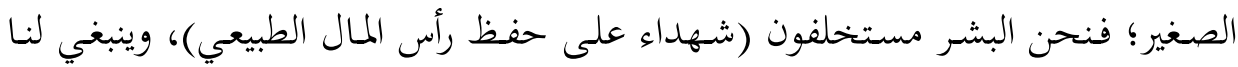

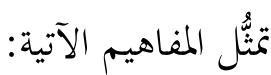

أ- إنّ الإنسـان والكون يسيران معاً في حالة تنـاغم وتسبيح. فالخلق كلّه غاية مـن

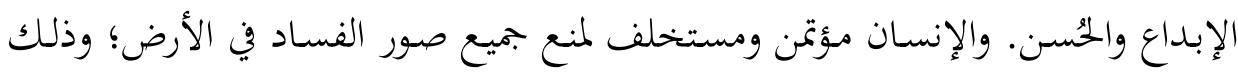
لضمان استمرار التنمية، وإعمار الكون.

بـ- إنّ عمـارة الكـون تتطلّب توازناً محكمـاً بـين رأس المـال الاجتمـاعي، والإنسـاني

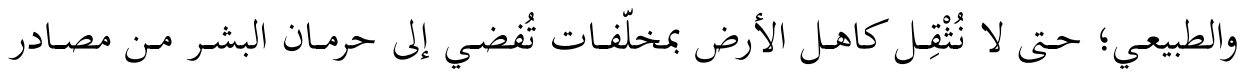
الطبيعة وخيراتها (من مثل: الطاقة، والغذاء)، وحتى لا ينتهي بنـا المطاف إلى إلى حالة "بئر

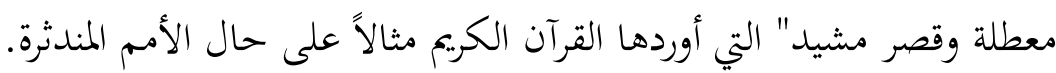
ت- - إنّ تعديل نمط الاستهلاك، وتمثُّل مبدأ "الزهد"، وتخفيف العبء عن كاهل هذه

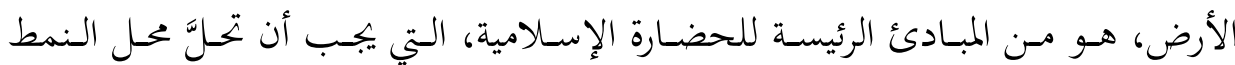

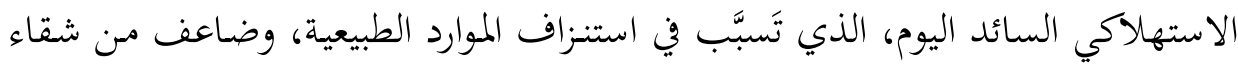


ث- - إنّ الاعتناء بصحة الإنسان، والمحافظة على موارد البيئة، ومكافحة الفقر، وصون

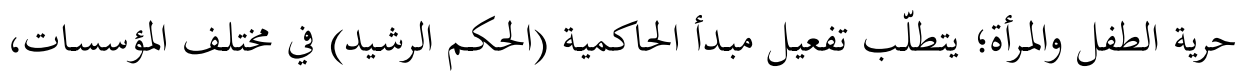

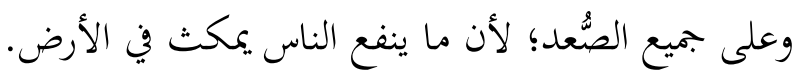

ج- إن التعلّم مـن الطبيعة، والتدبّر في ملكوت الأرض، هما مـن طرائف تنوير عقل

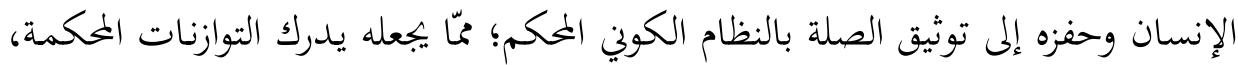

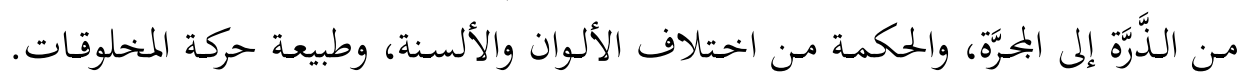
وعليه فإن فلسفة التنوع والاحتفال به (لا بحرد التعايش معه)، هي من صن صميم فهم قوله إنها

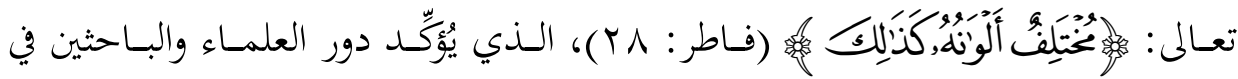

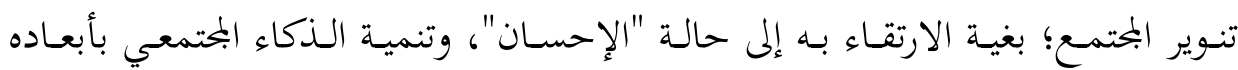
المختلفة، التي تتضمن الذكاء: البيئي، والوجودي، والتواصلي. ح- إنّ عولمة السوق الاقتصادية، تستدعي عولمة المحتمع المدلي؛ بغية إيجاد فئة مثقفة

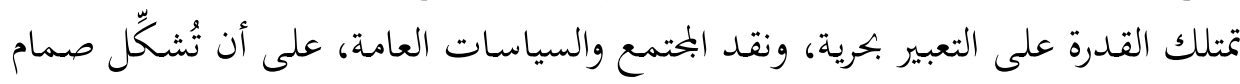

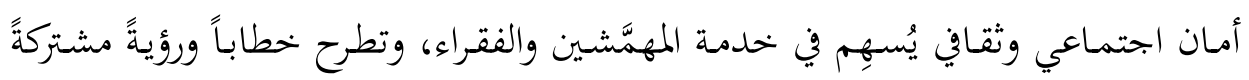
للتصالح مع كل ما يكيط بنا، ضمن منظومة متناغمة للاقتصاد والثقافة البيئية. وفي النهايـة لا يمكن تحديـد إطـار القيـادة الإنسـانية للعـالَّم بالـدول القطريـة، وقصـره

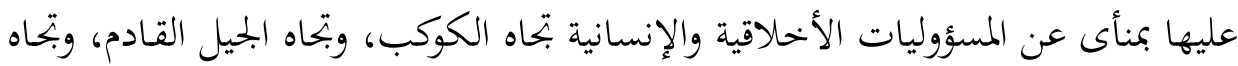

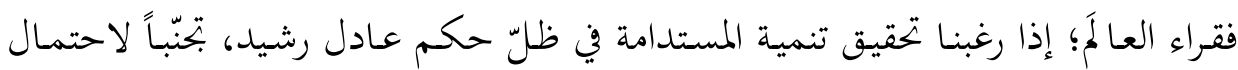
إن يؤول بنا المطاف إلى البئر المعطلة والقصر المشيد! 